\title{
The impact of gaze-based assistive technology on daily activities in children with severe physical impairments
}

\author{
Maria Borgestig
}

Division of Health, Activity and Care

Department of Social and Welfare Studies

Linköping University, Sweden

Linköping 2016

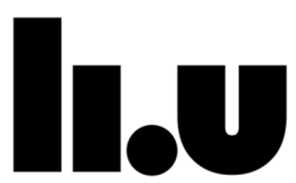

LINKÖPING UNIVERSITY 
Title: The impact of gaze-based assistive technology on daily activities in children with severe physical impairments

CMaria Borgestig, 2016

Cover Picture: FreeImages.com/Crissy Pauley

Published article has been reprinted with the permission of the copyright holder.

Printed in Sweden by LiU-Tryck, Linköping, Sweden, 2015

ISBN 978-91-7685-913-1

ISSN 0345-0082 


\section{CONTENTS}

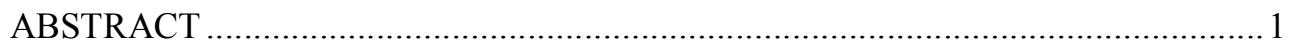

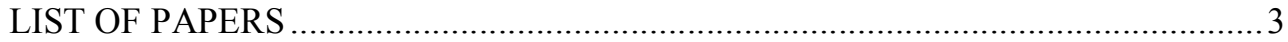

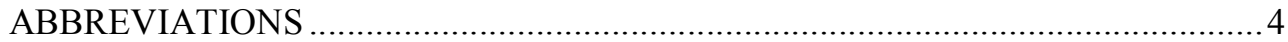

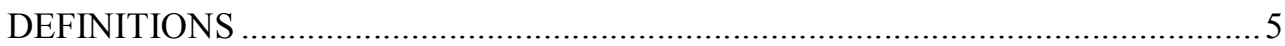

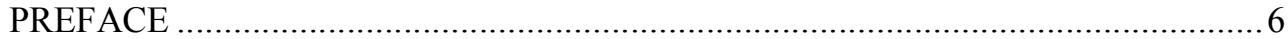

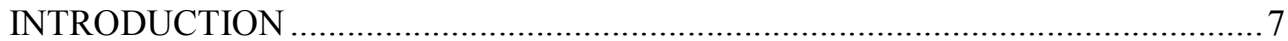

CHILDREN WITH SEVERE PHYSICAL IMPAIRMENTS WITHOUT

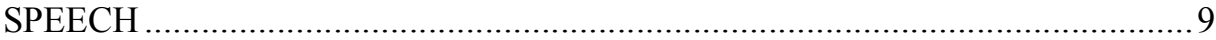

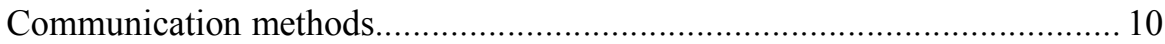

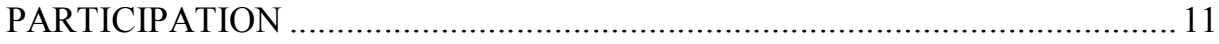

Participation in children with severe physical impairments ............................ 13

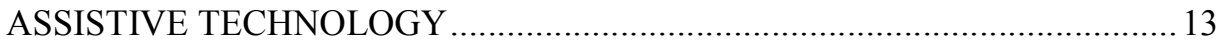

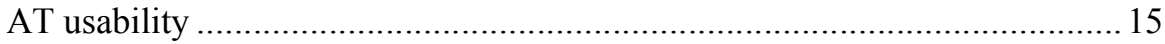

GAZE-BASED ASSISTIVE TECHNOLOGY ………................................... 16

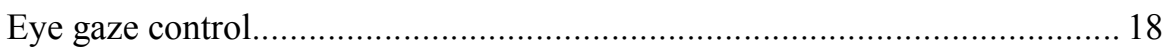

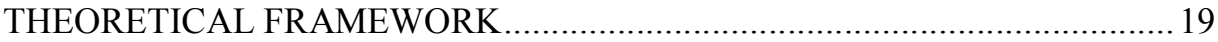

Human Activity Assistive Technology model (HAAT) ................................ 19

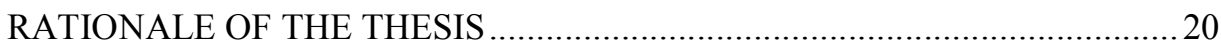

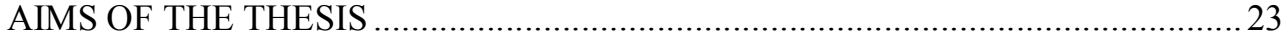

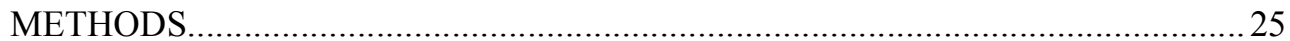

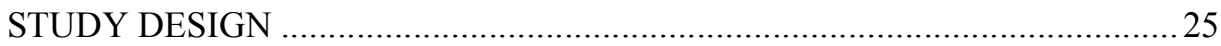

STUDY CONTEXT

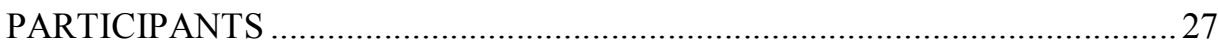

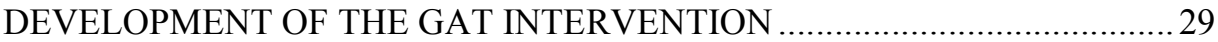

The AT intervention - the pilot study (Study I) ............................................30

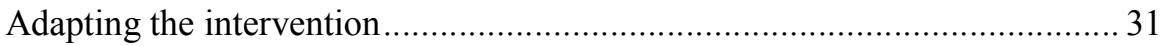

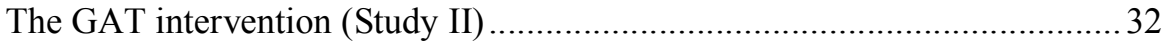

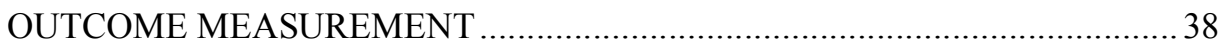

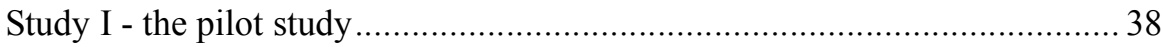




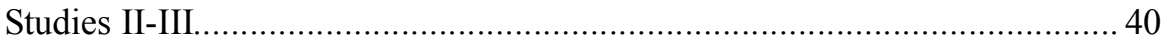

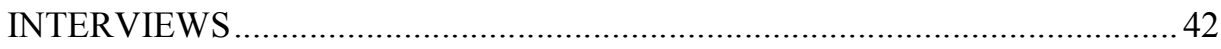

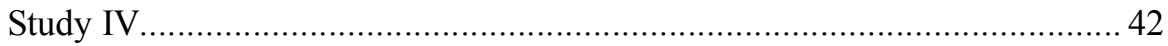

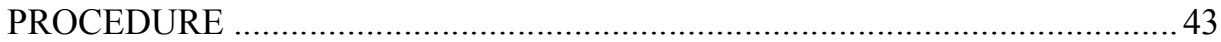

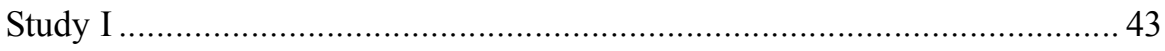

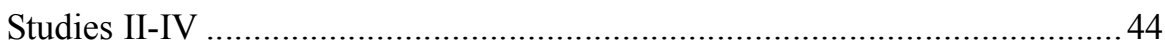

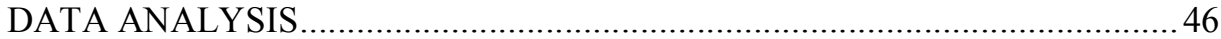

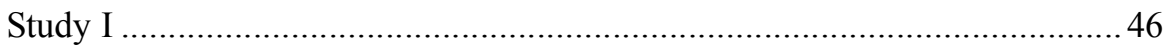

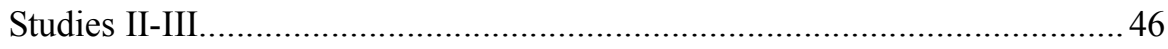

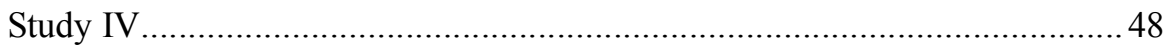

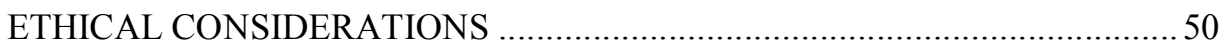

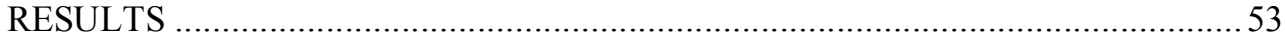

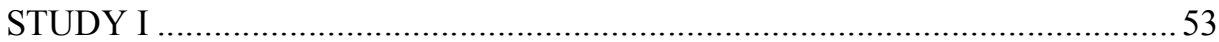

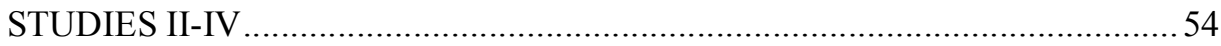

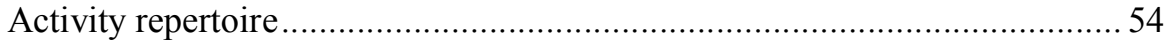

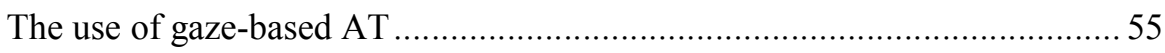

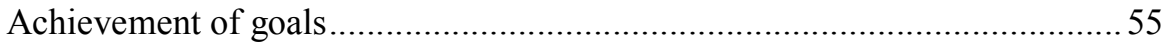

Parents' satisfaction of gaze-based AT ................................................. 56

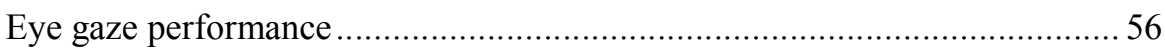

Hope of a better future - parents' experiences.................................... 58

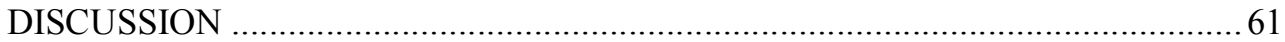

THE IMPACT OF ASSISTIVE TECHNOLOGY ON DAILY ACTIVITIES .....61

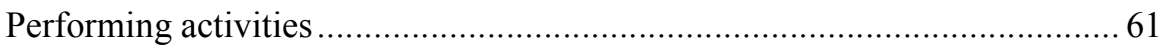

Increased activity repertoire .......................................................... 62

Communication and social interactions ..............................................6 64

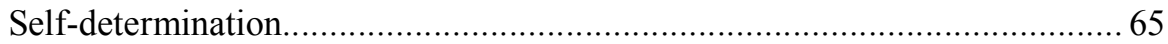

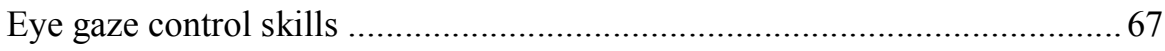

Participation in home and school settings ...........................................6 69

An occupational perspective on health .............................................. 71

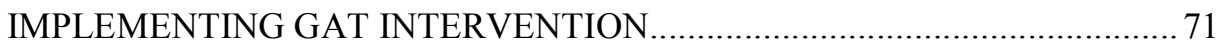

CLINICAL IMPLICATIONS ..................................................................... 74

METHODOLOGICAL CONSIDERATIONS ................................................. 75

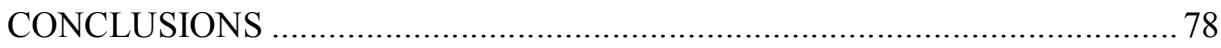




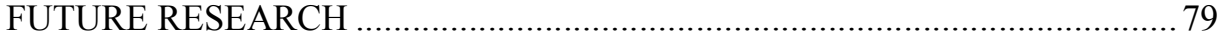

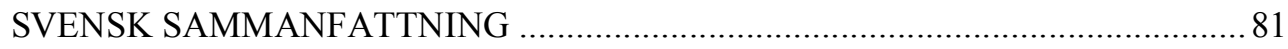

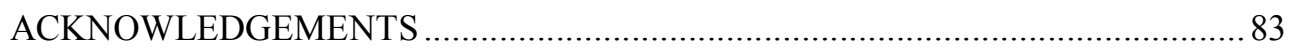

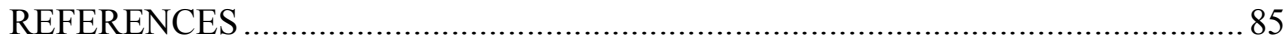





\section{ABSTRACT}

The aim of the thesis was to investigate the impact of gaze-based assistive technology on daily activities in children with severe physical impairments and without speech. The objectives were to develop and pilot a gaze-based assistive technology intervention (GAT intervention) at home and in school for these children and to understand its impact on daily activities as experienced by their parents.

Study I was a pilot study in which the basic components that were developed for the intervention were evaluated for students with physical impairments. The study aimed at improving the use of computers as assistive technology (AT) in school. Based on the findings in Study I, the GAT intervention was developed. The GAT intervention aimed at implementing gaze-based AT in daily activities. It consisted of two parts; having access to gaze-based AT and having access to services from a multi professional communication team during nine to ten months. Studies II-IV concerned gaze-based AT for children with severe physical impairments without speech who participated in the GAT intervention. The participants were ten children (ages 1-15) (Studies II, III), and their parents (Study IV). Studies II and III had longitudinal designs and children were followed during 15-20 months with repeated measurements before, after and at follow-up. In Study II children's repertoire of computer activities, extent of use, and goal attainment with gaze-based AT was evaluated, as well as parents' satisfaction with the AT and with services. In Study III children's eye gaze performance when using gaze-based AT was examined. In Study IV, parents were interviewed twice with the aim of exploring their experiences of children's gaze-based AT use in daily life. In Study IV a hermeneutical approach was used. 
The findings of Study I showed that the basic components of intervention improved the use of computers in school. Study II showed an increased repertoire of computer activities with the gaze-based AT, maintained use in daily activities for all at follow up, and that all children attained goals for gaze-based AT use in daily activities. Parents were satisfied with the gaze-based AT, and with the services in the GAT intervention. In study III, nine children improved in eye gaze performance over time when using the gaze-based AT in daily activities. Study IV revealed that children's gaze-based AT usage in daily activities made a difference to parents since the children demonstrated agency, and showed their personality and competencies by using gaze-based AT, and for the parents this opened up infinite possibilities for the child to do and learn things. Overall, children's gaze-based AT usage provided parents with hope of a future in which their children could develop and have influence in life.

In conclusion, this thesis shows that these children with severe physical impairments and without speech acquired sufficient gaze control skills to use gaze-based AT for daily activities in the home and at school. The gaze-based AT had a positive impact on performing activities, for example, play activities and communication- and interaction-related activities. For the parents, children's gaze-based AT usage made a difference since it shaped a hope of a better future for their children, where they can develop and gain influence in their future life. Furthermore, the children continued to perform daily activities with gaze-based AT over time. This finding suggests that key persons were provided with sufficient knowledge and skills to support children in maintained use of gazebased AT after withdrawal of the services provided in the GAT intervention.

Key words: cerebral palsy, computer activities, daily activities, eye gaze control, self-help devices 


\section{LIST OF PAPERS}

This thesis is based on the following papers, which will be referred to in the text by their Roman Numerals:

I. Borgestig, M., Falkmer, T., \& Hemmingsson, H. (2013). Improving computer usage for students with physical disabilities through a collaborative approach: A pilot study. Scandinavian Journal of Occupational Therapy 20(6), 463-470.

doi: $10.3109 / 11038128.2013 .837506$.

II. Borgestig, M., Sandqvist, J., Ahlsten, G., Falkmer, T., \& Hemmingsson, H. Gaze-based assistive technology in daily activities in children with severe physical impairments - an intervention study. Submitted.

III. Borgestig, M., Sandqvist, J., Parsons, R., Falkmer, T., \& Hemmingsson H. (2015). Eye gaze performance for children with severe physical impairments using gaze-based assistive technology-a longitudinal study. Assistive Technology. Published online.

doi:10.1080/10400435.2015.1092182

IV. Borgestig, M., Rytterström, P., \& Hemmingsson, H. Gaze-based assistive technology in daily life by children with severe physical impairments parents' experiences. Manuscript. 


\section{ABBREVIATIONS}

AT

GAS

GAT intervention

HAAT model

ICF

LPR centre

MPC team

PIADS
Assistive technology

Goal Attainment Scaling

Gaze-based assistive technology intervention

Human Activity Assistive Technology model

International Classification of Functioning, Disability

and Health

Local paedriatic rehabilitation centre

Multi professional communication team

Psychosocial Impact of Assistive Devices Scale 


\section{DEFINITIONS}

Assistive technology (AT)

Children with complex needs

GAT intervention

Gaze-based AT

Usability

Useworthiness
"An assistive product is any product (including devices, equipment, instruments and software), especially produced or generally available, used by or for persons with disability, for participation, to protect, support, train, measure or substitute for body functions / structures and activities, or to prevent impairments, activity limitations or participation restrictions."

(ISO, 2011)

in this thesis; children with severe physical impairments and without speech

consists of two parts; having access to gaze-based AT in daily activities and having access to services from a multi professional communication team

computer controlled by eye gaze

"the extent to which a product can be used by specified users to achieve specified goals with effectiveness, efficiency and satisfaction in a specified context of use" (ISO, 1998).

the extent to which an AT meet the individual's own high-priority needs

(Eftring, 1999) 


\section{PREFACE}

My clinical practice experience comprises my work as an occupational therapist in the field of paediatric rehabilitation for many years. Right from the start I was intrigued by children with profound impairments who could not speak or control any body movements except for their eye gaze, and who obviously had so much inside but struggled far too much to get us in the outside world to understand them. Together with children, parents, teachers and the communication team I was part of, I worked on finding some reliable type of body movement, such as head movement, that could be used to control a computer to communicate or perform activities. It was quite a revolution when gaze-controlled computers entered the clinical settings over the last decade and eventually started to be provided to children with profound impairments. I think all of us, including parents and teachers, saw the potential that gaze-based assistive technology (AT) had for these children.

Then, we started to hear feedback from professionals working with implementing gaze-based AT in children's daily lives. There were comments such as, 'That type of AT doesn't work for the children, it is no idea!' or 'He rarely uses it!' Such statements made me very curious and raised many questions. Can children really use it in real life situations, or only in an arranged situation at a clinic? What will make these ATs work? And what exactly do we mean when say that an AT works or does not work? These are all questions in need of answers.

At the same time, gaze-based AT was being prescribed to children while very little was known about what impact, if any, it had on children's daily activities. The limited knowledge made it problematic to know what to expect from its use, for parents, teachers, as well as for professionals. For the children's sake, we needed to seek more knowledge about this.

Maria Borgestig 


\section{INTRODUCTION}

The right for each child to develop to her full potential and fully participate in society is emphasized in the Convention of the Rights of the Child (United Nations, 1989). According to United Nations (1989) and Swedish law (Socialdepartementet, 2011), children with physical impairments have the right to live in conditions that promote their active participation in society, which includes the right to participate in play, leisure, and educational activities, as well as the right to express their own views freely in matters that affect them (United Nations, 1989). Children with severe physical impairments and without speech (referred to henceforth also as 'children with complex needs'), that cannot fully control any other body movements than their eye gaze, are dependent on assistance in all activities in daily life. Due to their severe motor impairments and communication difficulties they have extensive activity limitations and restricted opportunities to participate in daily activities, and their development is at risk (Bottcher, 2010). Interventions that promote their opportunities to take part in activities and express their needs should therefore be prioritized.

This thesis takes an occupational perspective and its starting position is that participation in occupations influences development and health (Kielhofner, 2008; Wilcock \& Hocking, 2015). In Occupational Therapy literature the term 'occupation' is used to denote all the things people do in their daily lives (Wilcock \& Hocking, 2015), and includes the activities people do to support their roles according to their own needs and preferences, for example a child being engaged in playful activities (Kielhofner, 2008; Wilcock \& Hocking, 2015). Through occupations, children discover ways of doing things, develop new skills, create knowledge and learn to express themselves (Davis \& Polatajko, 2006; Law, 2002; Kielhofner, 2008). The occupational repertoire changes over the life span due to age and child development (Davis \& Polatajko, 2006). 
The observable aspect of occupation is the activities individuals perform within their environment (Wilcock \& Hocking, 2015). The focus in this thesis is the daily activities children with severe physical impairments without speech perform in the home and at school, with 'activity' defined as a sequence of actions or tasks structured towards a goal. To perform an activity, the child needs to be aware of the goal for the activity and direct actions toward this goal. Daily activities is also seen as the medium through which the child interacts with the environment (Wilcock \& Hocking, 2015)

Within an occupational perspective, environment is described as being both a barrier to and an enabler of occupations and activities (Kielhofner, 2008; Wilcock \& Hocking, 2015). For children with impairments, physical and social aspects of environment will hinder or enable opportunities for activities and participation in daily life (Kielhofner, 2008; WHO, 2007). This is especially true for children with complex needs as they are totally dependent on people in their immediate environment in all daily activities. According to Kielhofner (2008), a change in the environment may initiate a change in the child's doing because it may create a better match between the child and the environment. For example, a computer controlled by eye gaze, gaze-based assistive technology (AT), may give opportunities for activities and participation for a child with complex needs (Majaranta et al., 2012). When learning to use an AT for activities, a child with complex needs will need assistance and support from people in the child's immediate environment (Cook \& Polgar, 2015). A child's learning is suggested by Vygotsky (2012) to occur through interaction with the environment. When a child learns to perform new activities, the process starts with joint activities with an adult, in which the adult mediates the child's development. Over time, the adult reduces the support and guidance to the child as the child becomes more independent in the activity (Case-Smith \& O'Brien, 2010; Vygotsky, 2012). Introducing gaze-based AT to non-speaking children with severe physical impairments requires assistance and support from people in the child's immediate environment. 
A few case studies indicate that gaze-based AT has the potential to support children's performance in activities such as playing games and communicating (Donegan et al., 2009; Donegan, 2012; Hornof \& Cavender, 2005; Lariviere, 2015; van Niekerk \& Tönsing, 2014). However, there is a lack of studies investigating the influence of gaze-based AT on children's daily activities. Therefore, this thesis focuses on non-speaking children with severe physical impairments that use gaze-based AT in daily activities at home and in school.

\section{CHILDREN WITH SEVERE PHYSICAL IMPAIRMENTS WITHOUT SPEECH}

Children with severe physical impairments and who are without speech represent a small group of children with physical impairments. Cerebral palsy is the most common cause of physical impairments, with a prevalence of two out of 1000 live births (Himmelmann, Hagberg, Beckung, Hagberg, \& Uvebrant, 2005). Only one third of those have a severe motor impairment and about one in four is without speech (Himmelman \& Uvebrant, 2011; Novak, Hines, Goldsmith, \& Barclay, 2012). The severe motor impairment and communication difficulties are often associated with concomitant impairments in perception and cognition, and can be accompanied by visual impairment, epilepsy and by secondary musculoskeletal difficulties (Rosenbaum et al., 2007). Due to the complex needs it may be difficult for children to participate in standardized assessments of cognitive function, which is why the cognitive level of these children is sometimes unclear (Yin Foo, Guppy, \& Johnston, 2013). Their severe motor impairment implies difficulties in controlling any body movement voluntarily, except for the eye movements. For example, children with the most severe physical impairments are not able to control their hand movements - for grasping, hand pointing or for making signs with the hands (Compagnone et al., 2014). They are therefore dependent on full assistance in all daily activities, such as to communicate, eat, or to play (Østensjø, Carlberg \& Vøllestad, 2005). 


\section{Communication methods}

To communicate with other people, children with complex needs need to rely on facial expressions and eye gaze as the main communication methods (Himmelmann, Lindh, \& Hidecker, 2013). Children with complex needs often retain relatively accurate in their eye movements (Beukelman \& Mirenda, 2013). Therefore, gaze-pointing at objects in the close environment can be used to request items, and using different facial expressions such as gazing in different directions or looking up and down can be used to communicate 'yes' and 'no' (Beukelman \& Mirenda, 2013; Myrden, Schudlo, Weyand, Zeyl \& Chau, 2014). This means that the initiative to communicate is usually with the communication partner, who needs to ask 'yes' and 'no' questions to the child for the child to be able to reply. The communication partner also needs to pay close attention to the child's eye gaze, facial expressions and body movements, by looking for changes in any movement to interpret the child's communication attempt. In addition, the partner needs to have some prior knowledge of the child's personal preferences to interpret the child's communication, which implies familiarity with the child (Myrden et al., 2014). Thus, interacting partners are limited and parents or other family members usually need to act as interpreters for their child (Hewitt-Taylor, 2008; Myrden et al., 2014).

To have opportunities to communicate is essential for all learning and children with complex needs are therefore at particular risk in their development (Light \& Drager, 2007; Light \& McNaughton, 2012). It is therefore important to provide children as early as possible with alternative modes of communication, such as single pictures, communication books or boards for gaze-pointing to support the development of communication (Light \& Drager, 2007; Beukelman \& Mirenda, 2013). Pictures for communication can also be put into electronic devices with speech output (Beukelman \& Mirenda, 2013). 


\section{PARTICIPATION}

The WHO (2007) emphasized that a person's functioning and disability are conceived as dynamic interactions between health conditions and contextual factors. Components of functioning and disability are divided into a body functions and body structures component, and into an activity and participation component. The concept of participation has been debated in particular detail in the literature and has been found to include different aspects. The International Classification of Functioning, Disability and Health (ICF) (WHO, 2007) defines participation as involvement in a life situation. Even though "being involved" may be considered to include the individual's own feelings of involvement, participation in ICF is operationalized as the observed performance in a specific context. Activity within ICF is defined as executing a task, and activity can also be understood as participation when activities are performed in a social and physical context that is natural for the individual (WHO, 2007). Hence, performing activities has been argued to be an aspect of participation (Arvidsson, Granlund, \& Thyberg, 2015; Molin, 2004; WHO, 2007). The ICF has been criticized for not including the individual's subjective experience of participation (Hemmingsson \& Jonsson, 2005). For example, a child with severe physical impairment may feel involved despite being unable to perform an activity (Hemmingsson, 2002; Pereira, La Cour, Jonsson, \& Hemmingsson, 2010). Feelings of involvement, regardless of whether the person is performing the activity or not, also need to be considered as participation (Almqvist \& Granlund, 2005; Pereira et al., 2010).

Another important aspect of participation is the experience of autonomy and selfdetermination. This aspect entails a subjective feeling of influencing the situation (Almqvist \& Granlund, 2005; Molin, 2004), and it can be defined as having a sense of control, choice, and mastery over the activity (Almqvist \& Granlund, 2005; Law, 2002; Molin, 2004). The definition of participation in the dictionary (Nationalencyklopedin, 2015) also emphasizes joint influence, which may be understood as involving interaction with other people. People's doing and 
interaction with other people have also been highlighted as a significant aspect of participation (Almqvist \& Granlund, 2005; Molin, 2004; Pereira et al., 2010). Social interaction requires actions from the individual and from the social environment in a give and take manner (Molin, 2004).

Within the context of the school setting, Pereira et al. (2010) found three forms of participation based on the subjective experiences of children with impairments. These three forms included both social aspects and performance characteristics: onlooker participation, special task participation, and equal participation. Equal participation meant that children with impairments performed activities with others and felt that they contributed equally; in special task participation, children with impairments were engaged in an activity with other children and contributed to the result but performed a different task that was adapted to the children's abilities. Onlooker participation was when children with impairments felt included even they only observed other children's doing, while non-participation occurred when children with impairments observed the other children's doing and felt excluded from the activity or were performed the activity without understanding. Thus, according to Pereira et al. (2010) children with impairments may experience participation either by performing activities or by feeling included without performing activities.

In this thesis, participation is understood as comprising the aspects of: children performing activities in their natural contexts of school and home, children's social interaction with people in their environment, and children's selfdetermination and autonomy as indicated by parents when observing their children in daily life. 


\section{Participation in children with severe physical impairments}

Children with complex needs have been found to be involved in few activities. Activities they are involved in are usually with the family and close to the home (Majnemer et al., 2008; Mei et al., 2015; Raghavendra, Virgo, Olsson, Connell, \& Lane, 2011; Thirumanickam, Raghavendra, \& Olsson, 2011). Children have also been found to have few interaction partners (Batorowicz, Campbell, von Tetzchner, King, \& Missiuna, 2014; Thirumanickam et al., 2011). In addition, Raghavendra et al. (2012) found missed opportunities for communication in school because children not were provided with opportunities to communicate using their AT. These children need support in doing activities and help in making activities available. Therefore, they are dependent on people in their immediate environment providing them with these opportunities (Raghavendra et al., 2011; Raghavendra et al., 2012; Thirumanickam et al., 2011).

Children with complex needs have difficulties in initiating interactions and need to rely on others wanting to communicate with them. These children are restricted in their ability to show competencies and parents experience their children to be misunderstood as not understanding or not wanting to interact due to their communication difficulties (Hewitt-Taylor, 2008). Parents of children with complex needs are concerned about the children's future and worry whether people will understand them, whether they will have some independence in the future, and whether they will achieve a sense of purpose in life (Antle, Mills, Steele, Kalnins, \& Rossen, 2008; Hewitt-Taylor, 2008).

\footnotetext{
ASSISTIVE TECHNOLOGY

AT in this thesis is defined in accordance with the commonly used definition of assistive products used by the International Organization for Standardization, (ISO, 2011), which states that "an assistive product is any product (including devices, equipment, instruments and software), especially produced or generally available, used by or for persons with disability, -for participation, -to protect,
} 
support, train, measure or substitute for body functions / structures and activities, or -to prevent impairments, activity limitations or participation restrictions." Computers used as AT can prevent activity limitations and participation restrictions for children with physical impairments by giving them access to a variety of activities in areas such as play (Chantry \& Dunford, 2010), communication (Chantry \& Dunford, 2010; Craddock, 2006; Salminen, Ryan, \& Petrie, 2004) and education (Chantry \& Dunford, 2010; Hoppestad, 2007; Priest $\&$ May, 2001). For example, computers used as AT in school have the potential to enable productivity and independence in educational tasks for children with physical impairments (Carpe, Harder, Tam, \& Reid, 2010; Copley \& Ziviani, 2007). Despite these benefits, computers in school have been found not to be used to their full potential to enable participation for this group of children (Brodin \& Renblad, 2009; Copley \& Ziviani, 2007; Hemmingsson, Lidström, \& Nygård, 2009; Lidström, Granlund, \& Hemmingsson, 2012). Furthermore, among children with severe physical impairments, underuse of AT provided for different purposes, such as communication, has been reported due to poor integration of AT in day-to-day contexts (Chantry \& Dunford, 2010; Hoppestad, 2007; Raghavendra et al., 2012). Overall, research indicates non-use of one third of AT provided to people with impairments (Scherer, 2002).

Provision of AT alone is not enough to guarantee usage of AT in daily life (Cook \& Polgar, 2015; Hoppestad, 2007; Scherer, 2002). To succeed in implementing AT into daily activities, AT interventions should involve having access to the particular AT and also to services provided by professionals experienced in AT (Lenker et al., 2010; Lindsay, 2010). The need for long-term services has also been stressed as important, to promote implementation and continued use of AT over time for non-speaking children with physical impairments (Anderson, Balandin, \& Stancliffe, 2013; Baxter, Enderby, Evans, \& Judge, 2012; Desideri et al., 2014; Salminen et al., 2004). 


\section{AT usability}

According to ISO (1998), product usability (9241-11:1998) is defined as the "extent to which a product can be used by specified users to achieve specified goals with effectiveness, efficiency and satisfaction in a specified context of use”. ISO (1998) defines effectiveness as the completeness of goals the user needs to achieve, efficiency as the resources expended during performance, and satisfaction as the attitudes towards the use of the product. Usability of an AT, by definition, should thus entail the impact it has on a user's performance of activities and participation in everyday life (Arthanat, Bauer, Lenker, Nochajski, $\& \mathrm{Wu}, 2007)$. The extent of AT use, such as the duration and frequency, and type of activities, has also been highlighted as an important usability indicator in the AT field (Cook \& Polgar, 2015; Lenker \& Paquet, 2004).

Another important indicator of usability is the learnability of the AT ( Lenker \& Paquet, 2004; Nielsen, 1993). Learnability is defined as how easy the device is to learn for a novice user and if skills can be remembered over time (Nielsen, 1993). Research indicates that there are learning effects over time from using a new AT for individuals with physical impairments (Caltenco, Breidegard, Jönsson, \& Andreasen Struijk, 2012; Donegan \& Oosthuizen, 2006; Jenko et al., 2010). Therefore, to understand the learnability of a specific AT, longitudinal research designs are needed. Another concept that has been stressed to be related to the usability of an AT is useworthiness (Eftring, 1999). Useworthiness is defined as the user's assessment of the extent to which the AT meets the user's own high priority needs. For users to determine what AT is worth using for, they need to be given opportunities to use their own initiative in choosing activities (Eftring, 1999). Thus, children's own choice of AT use may be an indication of the useworthiness of an AT. 


\section{GAZE-BASED ASSISTIVE TECHNOLOGY}

Children with complex needs who find it difficult to voluntarily control body parts other than their eye gaze have also difficulties with controlling any commonly used computer device, for example switches or special joysticks by hand, foot, head or mouth movements (Lidström \& Borgestig, 2008; Pfeiffer, 2013). For some of these children, eye gaze is the only option for controlling a computer and thereby gaining access to activities such as communication and playing games (Majaranta \& Donegan, 2012). Gaze-based AT is a computer controlled by eye gaze, in which the eye gaze replaces the keyboard and mouse as the interface method (Lin, Yang, Lay, \& Yang, 2011; Majaranta \& Donegan, 2012). Eye gaze control means that the user points at objects on the computer screen by moving the eyes and makes selections by fixating on an object during a pre-specified dwell-time (Hansen \& Majaranta, 2012). Dwell-time is the duration of a fixation on a certain target (Pfeiffer, 2013). Gaze-based AT has the potential to enable independent communication and performance of activities for children with complex needs (Majaranta et al., 2012). Software with a grid-based solution on screen is often used in gaze-based AT. This includes dynamic pages that are individually adapted with pictures to meet each child's activity needs (Pfeiffer, 2013).

Most research concerning gaze-based AT is related to the development of new products for eye gaze control for people with motor impairments. These products are tested under experimental conditions involving people with or without impairments (Chin, Barreto, Cremades, \& Adjouadi, 2008; Diard, Rynik, \& Lorenceau, 2013; Pasqualotto et al., 2015). Research on the benefits of using gaze-based AT in daily activities for people with physical impairments is sparse. Survey studies of adults with amyotrophic lateral sclerosis (ALS), using gazebased AT have reported outcomes of improved quality of life (Hwang, Weng, Wang, Tsai, \& Chang, 2014), satisfaction with gaze-based AT (Caligari, Godi, Guglielmetti, Franchignoni, \& Nardone, 2013), and that gaze-based AT enhanced the performance of activities such as communication face-to-face, e-mail, and 
internet surfing (Ball et al., 2010; Caligari et al., 2013; Hwang et al., 2014; Spataro, Ciriacono, Manno, \& La Bella, 2014).

There is a dearth of studies investigating the use and benefits of gaze-based AT in daily life for children with severe physical impairments. Some user trials claim that gaze-based AT can enable children with complex needs to perform activities, such as playing games, playing music, and making drawings (Donegan et al., 2009; Hornof \& Cavender, 2005; Lariviere, 2015). Two case studies investigated the use of gaze-based AT in daily activities by children with cerebral palsy (Donegan, 2012; van Niekerk \& Tönsing, 2014). These case studies reported gaze-based AT usage for playing music, storytelling in school (Donegan, 2012) and for communication and literacy training in school and home (van Niekerk \& Tönsing, 2014). Usability in terms of completeness of goals or extent of gazebased AT use was not reported in any of these studies. The gaze-based AT was reported to be underutilized in one of the studies due to lack of services assisting the AT implementation process (van Niekerk \& Tönsing, 2014). Donegan (2012) highlighted that the gaze-based AT needed to be implemented for an extended period of time to maintain the child's interest and motivation in its use.

In Sweden, children with complex needs can be prescribed a gaze-based AT payed by the County Council. Gaze-based AT is typically provided to those who need to use it for communication due to communication impairments, for example adults with ALS or children with complex needs. Based on data from four out of 21 counties in Sweden (two of the three largest and two smaller counties) representing $36 \%$ of the Swedish population, a total of approximately 45 children with physical impairments and without speech use gaze-based AT in their daily life within these counties (personal communication, 2015). 


\section{Eye gaze control}

Eye gaze control requires the ability to voluntarily gaze point at objects on a screen and select objects through fixating on an object for a certain period of time (Majaranta \& Donegan, 2012; Mulvey, 2012). Gaze pointing is considered as a natural and intuitive method as the human eye consciously directs attention towards objects of interest (Majaranta \& Donegan, 2012; Stampe \& Reingold, 1995). The human eye is a sensory organ and is developed to perceive information from the outside world. Therefore, using the eyes for selecting objects goes beyond its natural sensory use (Hansen \& Aoki, 2011; Heikkilää \& Ovaska, 2012; Skovsgaard, Räihä, \& Tall, 2012). Fixations typically made by the human eye to explore the environment are often shorter than $250 \mathrm{~ms}$ but can sometimes go up well above this if the individual performs decision-making tasks (Godijn \& Theeuwes, 2004; Mulvey \& Heubner, 2011; Pfeiffer, 2013). The threshold to make selections (fixation duration) while using gaze-based AT must therefore be for a longer duration than a typical human fixation to avoid unintentional selections (Godijn \& Theeuwes, 2004; Pfeiffer, 2013). In addition, eye movements are related to visual attention and interest. Therefore, using eye gaze for eye gaze control requires that the individual remains attentive and motivated to complete the whole task (Mulvey \& Heubner, 2011).

Researchers propose that it may be challenging to learn how to eye gaze control objects on a computer screen (Hansen \& Aoki, 2011; Heikkilää \& Ovaska, 2012; Skovsgaard et al., 2012). This seems to be the case for individuals with severe physical impairments, as case studies have shown that eye gaze control can be tiresome and may lead to exhaustion during early stages of use for these individuals (Donegan, 2012; Najafi, Friday, \& Robertson, 2008).

Familiarization with gaze-based AT and the learning effect from using this AT over time are suggested to be especially important for eye gaze control compared to other computer input methods. This is because it is not natural to control an interface with eye gaze. All users of eye gaze control will be novices at first, 
since no one can have any previous experience of controlling the outside world with eye gaze (Hansen \& Aoki, 2011). Over time the interaction with the computer may become faster and smoother due to learning to use the AT (Heikkilää \& Ovaska, 2012). Case studies indicate that to learn gaze control smaller targets on screen several months of practice may be needed for individuals with complex physical and visual difficulties (Donegan, 2012; Donegan \& Oosthuizen, 2006). Two case studies that intended to evaluate eye gaze control of computer for children with cerebral palsy found that the selected system was not suitable for these children due to their involuntary movements (Dhas, Samuel, \& Manigandan, 2014; Man \& Wong, 2007). Hence, for individuals with cerebral palsy it is important to try gaze-based AT systems that can detect the eye gaze despite involuntary body movements.

\section{THEORETICAL FRAMEWORK}

The Human Activity Assistive Technology model (HAAT) (Cook \& Polgar, 2015) is used in this thesis as this model specifically highlights the AT and provides theoretical reasoning of how AT works in contexts for individuals with impairments (Cook \& Polgar, 2015; Arthanat et al., 2007).

\section{Human Activity Assistive Technology model (HAAT)}

The HAAT model, developed by Cook and Polgar (2015), is a framework that defines the AT system as the dynamic interaction between the human, the activity and the AT in the specific contexts in which the AT is used. All these parts are seen as having impacts on activity performance in daily activities and systematic consideration of all four parts will therefore reduce the risk of underutilization or abandonment of AT (Cook \& Polgar, 2015, Lenker \& Paquet, 2003). 
The human as a novice user of an AT means that there is little or no previous experience of the AT. However, a user becomes more of an expert by practicing and gaining experience from the AT use, leading to a higher degree of skill in AT usage. A child that is a novice user needs to exert more conscious effort to operate an AT than a child that is more of an expert user. The activity is specifically highlighted as the fundamental element in the HAAT model and its relevance to the child is seen to be paramount. Performing activities also defines the overall goal of the AT system (Cook \& Polgar, 2015). The AT facilitates the child's accomplishment of activities (Arthanat et al., 2007). The output from gaze-based AT when the child has made a selection takes the form of a changed view on the screen display, and speech output of a message from a speech synthesizer. The contexts, defined as the social, physical, cultural and institutional contexts, in which the activity is performed can enable and/or be a barrier to the performance of activities with AT. The social context is often the most important context for AT use and comprises the individuals interacting directly or indirectly with the child that uses the AT. Their understanding of the need for and purpose of the AT and how the AT works is critical for successful performance of activities with AT. When providing a child with an AT strategies for adaptations both of the AT software and in how to give support to the child is needed, to optimize the process of learning how to use the AT. Policies and regulations concerning AT services form the institutional context will determine who will have access to an AT and to services (Cook \& Polgar, 2015).

\section{RATIONALE OF THE THESIS}

This thesis addresses a new topic of research by investigating outcomes from the use of gaze-based AT in daily activities for children with severe physical impairments and without speech. Gaze-based AT is a relatively new AT for this group of children, and key persons may have considered it as expensive until recently. Another reason it has not been widely used may be that professionals feel uncertain about whether children can acquire sufficient gaze control skills to 
use gaze-based AT for daily activities. In addition, there is a lack of studies that can inform professionals on these matters. As a consequence, few children with complex needs have had access to gaze-based AT, even though it might be their only option to perform activities. A gaze-based AT that can overcome some of these children's profound activity limitations might indeed make a huge difference between being able, and not being able to perform activities. The potential a gaze-based AT has to make such a difference for the children offers a great opportunity for scientific enquiry.

Evaluations targeted at investigating the impact of gaze-based AT on children's daily activities will also be of interest for clinical practice. Such evaluations may inform professionals about realistic expectations when implementing gaze-based AT in schools and at home. However, there is unfortunately a dearth of studies investigating which kind of AT services will best meet the needs of these children, and of studies identifying the key persons to optimize the implementation and usage of gaze-based AT. The research presented in this thesis is thus timely and bridges a recognised gap in the literature. 


\section{AIMS OF THE THESIS}

The aim of the thesis was to investigate the impact of gaze-based assistive technology on daily activities in children with severe physical impairments and without speech. The objectives were to develop and pilot a gaze-based assistive technology intervention (GAT intervention) at home and in school for these children and to understand its impact on daily activities as experienced by their parents.

The aims of the specific studies were:

- to evaluate the effect of an AT intervention to improve the use of available computers as AT in educational tasks for students with physical impairments during an ongoing school year (Study I)

- to establish the impact of a gaze-based AT intervention on activity repertoire, autonomous usage, and goal attainment in children with severe physical impairments. In addition, parents' satisfaction with the gaze-based AT and with services related to the gaze-based AT intervention was examined (Study II)

- to examine changes of eye gaze performance over time (time on task and accuracy) in children with severe physical impairments, without speaking ability, using gaze-based AT (Study III)

- to describe and explore what it means to parents when their nonspeaking children with severe physical impairments receive a gaze-based AT to use in daily life (Study IV) 


\section{METHODS}

\section{STUDY DESIGN}

This thesis consists of four studies, one of which was a pilot study (Study I) for the development of a gaze-based AT intervention (GAT intervention). The three remaining studies involved the implementation and use of gaze-based AT at home and at school for children with severe physical impairments (Studies IIIV). Study I and Studies II-III used longitudinal designs (Polit \& Beck, 2008) and Study IV took a qualitative approach (Patton, 2002).

The GAT intervention was developed by the research group. The studies were conducted in a specific order, as the intervention was developed in two steps. First, the basic components of the intervention were evaluated in a pilot study for speaking students with physical impairments in schools (Study I). Thereafter, the intervention was adapted for non-speaking children with severe physical impairments. Following this, Study II examined the use of gaze-based AT in daily activities. In Study III, the focus was on children's eye gaze performance during interaction with the gaze-based AT, and Study IV explored parents' experiences of children's use of gaze-based AT in daily life. In Study IV, interviews were conducted with parents whose children participated in the GAT intervention. A hermeneutical approach was used (Gadamer, 2004) in Study IV in order to go beyond the immediate content of the parents' stories, to explore and understand their experiences of their children's use of gaze-based AT in daily life. For an overview of the studies, see Table 1. 
Table 1. Overview of the studies in the thesis.

\begin{tabular}{|c|c|c|c|c|}
\hline & Study I & Study II & Study III & Study IV \\
\hline Objective & $\begin{array}{l}\text { The AT } \\
\text { intervention } \\
\text { (Basic components } \\
\text { in intervention) }\end{array}$ & $\begin{array}{l}\text { The use of gaze- } \\
\text { based AT in daily } \\
\text { activities } \\
\text { (GAT intervention) }\end{array}$ & $\begin{array}{l}\text { Examination of } \\
\text { eye gaze } \\
\text { performance } \\
\text { (GAT intervention) }\end{array}$ & $\begin{array}{l}\text { Parents' } \\
\text { experiences of } \\
\text { children's gaze- } \\
\text { based AT usage }\end{array}$ \\
\hline Design & $\begin{array}{l}\text { Before, after and } \\
\text { follow up }\end{array}$ & $\begin{array}{l}\text { Before, during, } \\
\text { after and follow } \\
\text { up }\end{array}$ & $\begin{array}{l}\text { Before, during, } \\
\text { after and follow } \\
\text { up }\end{array}$ & $\begin{array}{l}\text { A hermeneutical } \\
\text { approach }\end{array}$ \\
\hline $\begin{array}{l}\text { Assistive } \\
\text { technology }\end{array}$ & $\begin{array}{l}\text { Ordinary } \\
\text { computer as AT }\end{array}$ & Gaze-based AT & Gaze-based AT & Gaze-based AT \\
\hline Participants & $\begin{array}{l}15 \text { speaking } \\
\text { students with } \\
\text { physical } \\
\text { impairments (ages } \\
12-18 \text { ) and } 16 \\
\text { teachers. }\end{array}$ & $\begin{array}{l}10 \text { children with } \\
\text { severe physical } \\
\text { impairments } \\
\text { without speech } \\
\text { (ages 1-15). }\end{array}$ & $\begin{array}{l}\text { The same as in } \\
\text { Study II }\end{array}$ & $\begin{array}{l}11 \text { parents to eight } \\
\text { children in Studies } \\
\text { II and III. }\end{array}$ \\
\hline $\begin{array}{l}\text { Data } \\
\text { Collection }\end{array}$ & $\begin{array}{l}\text { Observations on } \\
\text { computer use and } \\
\text { goal attainment }\end{array}$ & $\begin{array}{l}\text { Observations on } \\
\text { computer use, } \\
\text { goal attainment, } \\
\text { and satisfaction } \\
\text { questionnaire }\end{array}$ & $\begin{array}{l}\text { Assessment of } \\
\text { eye gaze } \\
\text { performance } \\
\text { during interaction } \\
\text { with the gaze- } \\
\text { based AT }\end{array}$ & $\begin{array}{l}\text { Semi-structured } \\
\text { interviews }\end{array}$ \\
\hline $\begin{array}{l}\text { Time points } \\
\text { for data } \\
\text { collection }\end{array}$ & $\begin{array}{l}\text { Baseline, } \\
2 \text { months, } \\
4 \text { months }\end{array}$ & $\begin{array}{l}\text { Baseline, } \\
\text { 5months, } \\
9-10 \text { months, } \\
15-20 \text { months }\end{array}$ & $\begin{array}{l}\text { Baseline, } \\
5 \text { months } \\
9-11 \text { months, } \\
15-20 \text { months }\end{array}$ & $\begin{array}{l}\text { At the beginning } \\
\text { of children's gaze- } \\
\text { based AT usage, } \\
\text { and about one year } \\
\text { later }\end{array}$ \\
\hline $\begin{array}{l}\text { Data } \\
\text { analysis }\end{array}$ & $\begin{array}{l}\text { Non-parametric } \\
\text { statistics }\end{array}$ & $\begin{array}{l}\text { Visual analysis } \\
\text { and Descriptive } \\
\text { statistics }\end{array}$ & $\begin{array}{l}\text { Statistical } \\
\text { analysis for } \\
\text { clustered data }\end{array}$ & $\begin{array}{l}\text { Hermeneutical } \\
\text { interpretation }\end{array}$ \\
\hline
\end{tabular}

\section{STUDY CONTEXT}

In Study I, participants attended mainstream schools, and the AT intervention was implemented in their school settings. The AT intervention was provided by the research group, together with an occupational therapist from an Assistive Technology centre and two special teachers from the National Agency for Special Needs Education and Schools. All professionals were specialised in the use of computer as AT in schools for students with physical impairments. 
In Studies II-IV, the GAT intervention was provided by a multi-professional communication team (MPC team) at a regional paediatric rehabilitation centre. Local paediatric rehabilitation centres (LPR centres), one in each county council in Sweden, are responsible for the long-term rehabilitation of children with physical impairments in Sweden, up to the age of 21. The LPR centres can refer children to the regional paediatric centre for assessment, intervention or followup during shorter time periods and for specific issues. The LPR centres in seven county councils in central Sweden form the primary catchment area for referrals to the regional paediatric rehabilitation centre in terms of gaze-based AT. The MPC team at the regional centre in Studies II-IV was specialised in AT for communication in children with physical impairments, and was experienced and well-trained in gaze-based AT. The team consisted of an occupational therapist, a speech and language therapist, a special teacher and an IT support person. A paediatric neurologist was involved as a medical expert.

\section{PARTICIPANTS}

Study I involved the participation of 15 students with physical impairments who attended 14 different mainstream schools. They each chose a teacher from their school to participate with them. These students were recruited from an earlier survey study focused on the use of computer as AT by students with physical impairments, including 287 students from central Sweden (Lidström, Almqvist, \& Hemmingsson, 2012). The inclusion criteria for Study I stipulated that students 1) had a physical impairment, 2) were aged 12-18, 3) had reported in the survey study that they wished to use available computers more often in school and 4) were positive about participating in future research. Using random selection $(n=83$ met the inclusion criteria), continuous invitations were sent until 15 students had agreed to participate (32 students were invited; 14 declined and three did not respond to the invitation). All the teachers who had been invited agreed to participate. One student chose two teachers to participate, so 16 teachers were included in the study in total. The participating students ( 9 boys 6 
girls) had a mean age of 15 (SD 1.6) and all could speak. Most students had a diagnosis of cerebral palsy, and the second most common diagnosis was spina bifida. Seven out of 15 used mobility aids. They attended compulsory school $(\mathrm{n}=10)$ or upper secondary school $(\mathrm{n}=5)$.

Participants in Studies II and III are shown in Table 2. In Studies II and III, all children were included $(n=10)$ who had been referred by LPR centres to the regional paediatric rehabilitation centre during the period 2010 to 2013, and had fulfilled the following inclusion criteria: 1) children with severe physical impairments, without speech, 2) up to 18 years of age, 3) access to gaze-based AT, 4) parents and teacher had agreed to participate in the GAT intervention and in data collection. All parents and teachers for the ten children agreed to participate in the studies. All children had a severe motor impairment, with cerebral palsy as the most common diagnosis. Additional impairments are shown in Table 2. In terms of body movements, they had the best control over their eye movements, and needed assistance throughout the day in all activities. None were able to speak, and they communicated with facial expressions and through eye gaze. Most children could indicate yes or no by eye gaze or facial expressions, although some children were unclear in this. Two children had alternating strabismus.

In Study IV, 11 parents to eight children from Studies II and III, participated. The inclusion criteria involved parents whose child had started the GAT intervention sometime between 2010 and 2013, planned to use gaze-based AT at home, and had finished the intervention in January 2014 at the latest. Planned use of gazebased AT at home was included as a criterion so that parents would gain experiences in their children's use of the AT. The parents of eight children met the inclusion criteria, and all these parents agreed to participate. The time frame for the inclusion criteria was set to allow time to complete the data collection. As a result of the criteria, the children of the participating parents were 5 to 15 years of age. Parents had a mean age of 42.2 (SD 3.2). Both parents participated in the 
case of three children, and one parent in the case of five children. The 11 parents consisted of five fathers and six mothers.

Table 2. Characteristics for participants in Studies II-III.

\begin{tabular}{ll}
\hline & $\mathbf{n = 1 0}$ \\
\hline Age, mean (sd) & $8.6(4.6)$ \\
Boys/girls & $8 / 2$ \\
School & $2 / 6 / 1$ \\
$\begin{array}{l}\text { Compulsory school / special school / special preschool } \\
\text { Diagnosis }\end{array}$ & 9 \\
Cerebral Palsy & 1 \\
High cervical spinal cord injury & \\
Gross motor function & \\
(Gross Motor Function Classification System, GMFCS)* & 4 \\
Level IV & 5 \\
Level V & \\
Manual ability & \\
(Manual Ability Classification System, MACS)* & 5 \\
Level IV & 4 \\
Level V & \\
Communication & \\
(Communication Function Classification System, CFCS)* & \\
Level IV & 7 \\
Level V & 2 \\
Cognition & \\
Normal & 3 \\
Unspecified impairment & 5 \\
Unknown \\
Epilepsy
\end{tabular}

\section{DEVELOPMENT OF THE GAT INTERVENTION}

The GAT intervention was developed in two steps. The first step (called the AT intervention) was evaluated in a pilot study (Study I) for children with mild physical impairments. This procedure was necessary, as children with severe physical impairments are a vulnerable group (Beckung \& Hagberg, 2002; Beckung et al., 2008). Therefore, the basic components of the intervention were evaluated first, to check that they worked appropriately, before the intervention was developed further for children with complex needs. In addition, case studies indicated the need for the children to use gaze-based AT for longer periods of time (from several months to a year) to learn gaze control skills (Donegan, 2012; 
Donegan \& Oosthuizen, 2006). This also confirmed the need to know more about the effect of basic components before implementing the intervention with these children for such a long time period. Thus, the pilot study was conducted to evaluate the basic components in the intervention, the testing procedure, the instruments and the feasibility of using goal setting in intervention. Thereafter, the intervention was adapted for non-speaking children with severe physical impairments, and called 'GAT intervention'. The GAT intervention was then evaluated in Study II in terms of daily activities for the target group involved in this thesis.

\section{The AT intervention - the pilot study (Study I)}

The AT intervention was developed by the research group to improve the use of available computers in schools. The intervention was based on key elements found to be essential for the success of interventions involving children with physical impairments. These key elements are shown in Table 3. The rationale for basing an intervention on these key elements was that, by (a) increasing teachers' knowledge, (b) involving the student in decision-making, (c) enhancing collaboration between student, teacher and occupational therapist, and (d) setting goals for computer use in educational tasks, teachers could be empowered to support students in using computers for their individual needs. This, in turn, could lead to improvements in the students' use of computers to overcome participatory restrictions in educational tasks.

Two basic components were constructed based on the key elements, and these were evaluated during the pilot study: a group course day and an individual planning meeting. Firstly, the course day consisted of educating teachers in how using computers at school could enhance participation. It also involved a demonstration of tools (e.g. listening to e-books for supporting reading), and teachers exchanged experiences about computer use at school. The planning meeting (2h) followed this, involving the student, teacher and occupational 
therapist. It was built on collaborative consultation (Villeneuve, 2009), and consisted of discussing the student's current computer use, identifying participation restrictions in educational tasks, formulating goals for computer use and developing computer-based strategies to overcome the identified participatory restrictions. Collaborative consultation is an interactive process enabling people with diverse expertize to create solutions on mutually defined problems (Villeneuve, 2009). After this meeting, no more support was provided, and teachers were responsible for implementing the computer-based strategies in their school.

\section{Adapting the intervention}

After the pilot study, the intervention was adapted. Adaptations were based on the findings of the pilot study that teachers might need more support to implement computer-based strategies, as not all goals were achieved at followup. Further adaptations were also made after discussions between the research group and a number of professionals involved in service delivery for nonspeaking children with severe physical impairments. As a result of discussing the format, content and implementation of the intervention for children with complex needs, more course days were added, along with follow-up meetings and individual support.

In summary, the adaptations involved: (a) expanding the number of course days and collaborative meetings for teachers and parents, and holding joint follow-up meetings for all involved, (b) adding individual support due to the children's complex needs, and (c) extending the time period for delivering the intervention to 9-10 months. This time period was based on case studies indicating the need for individuals with complex needs to practise eye gaze control skills for several months (Donegan, 2012; Donegan \& Oosthuizen, 2006), and the need for key persons around them to acquire knowledge and skills (e.g. handling technology, adapting the content, supporting the child in its use) to promote sustained AT use 
over time (Anderson et al., 2013; Desideri et al., 2014; van Niekerk \& Tönsing, 2014).

Table 3. Key elements in intervention

\begin{tabular}{llc}
\hline & Key elements & Study \\
\hline 1 & $\begin{array}{l}\text { Increase teachers' knowledge of the use of computers as AT in educational tasks for } \\
\text { children with physical impairments }\end{array}$ & I, II \\
2 & $\begin{array}{l}\text { Student's/child's involvement and preferences for use of computer as AT } \\
2\end{array}$ & I, II \\
3 & Goal setting for computer use of AT in educational tasks $^{3}$ & I, II \\
4 & Collaboration between all key persons; e.g. occupational therapist, teacher and student $^{4}$ & I, II \\
5 & Teachers' involvement should not be time-consuming $^{5}$ & I, II \\
6 & Involving parents in decision-making, including families priorities of goals for AT use $^{6}$ & II \\
\hline
\end{tabular}

\section{The GAT intervention (Study II)}

The GAT intervention consisted of children having access to gaze-based AT in daily activities, and access to services from the MPC team for a period of 9-10 months. When the GAT intervention ended (after 9-10 months), the services of the MPC team at the regional paediatric rehabilitation centre were terminated. The children then continued to have full access to gaze-based AT in their daily lives. They also maintained contact with their team at the LPR centre, which provided their families with long-term support.

\section{Gaze-based AT}

The gaze-based AT products used in Studies II-IV were a Tobii C12 (n=9) and a P10 ( $n=1)$ by Tobii Technology. Both devices were built-in systems with eye camera, eye-control functions, and the screen incorporated as a single unit (Tobii Technology, 2013). The C12 had a 12" screen with an optimal working distance of $23.5 "(60 \mathrm{~cm})$ between eyes and screen, and the P10 had a 15" screen with an optimal distance of 20-28” (50-71 cm). Involuntary head movements had to be

1 (Copley \& Ziviani, 2004; Brodin \& Lindstrand, 2003; Hasselbring \& Glaser, 2000)

2 (Hemmingsson, Lidström \& Nygård, 2009; Hoppestad, 2007; Martin, Martin, Stumbo \& Morrill, 2010)

3 (Copley \& Ziviani, 2004; Hoppestad, 2007; Rose, Hasselbring, Stahl \& Zabala, 2005)

${ }_{5}^{4}$ Dettmer, Dyck \& Thurston, 2002; Villeneuve, 2009; Hemmingsson, Gustavsson \& Townsend, 2007)

${ }_{6}^{5}$ (Brodin \& Lindstrand, 2003; Lenker, Fuhrer, Jutai, Demers, Scherer \& DeRuyter, 2010)

${ }^{6}$ (Baxter, Enderby, Evans \& Judge, 2012; Granlund, Björck-Åkesson, Wilder \& Ylvén, 2008) 
taken into account in individuals with cerebral palsy, so devices for eye gaze control needed to allow for head movements (Donegan, 2012). The C12 and P10 devices allowed for the following range of head movements: $15.7 \times 11.8 \times 7.9$ in $(\mathrm{C} 12)$ and $12 \times 6 \times 8$ in $(\mathrm{P} 10)$. The eye camera reads with an accuracy of 0.8 degrees (C12) and 0.5 degrees (P10) when estimating gaze in the user's visual field (Tobii Technology, 2013). Gaze calibration for each user was performed before use, in order to obtain reliable results when the child use gaze control to operate the computer. Both devices needed to detect at least one eye for the system to work. The children control the computer by gazing at objects on the screen, and then selecting an object by fixating their gaze on it for a pre-specified dwell time. Usually this period of time is specified within a range of $0.5-1.0$ seconds.

Both devices were portable and were mounted on a floor stand, table stand or on the wheelchair (see Figure 1). The gaze-based AT was transported with the child between home and school. During the GAT intervention, the software in the gaze-based AT was adapted to include dynamic communication pages with pictures, symbols and speech output, to meet each child's individual needs in terms of daily activities at home and/or at school. According to the different ages and cognitive levels, pages were developed for play and leisure, educational tasks and for communication. The number of pictures on a page varied between three and 25 , with a variation of between 60 and 800 pictures in total by the time the children had finished the services in the GAT intervention. For an example of a page in the gaze-based AT, see Figure 2. 


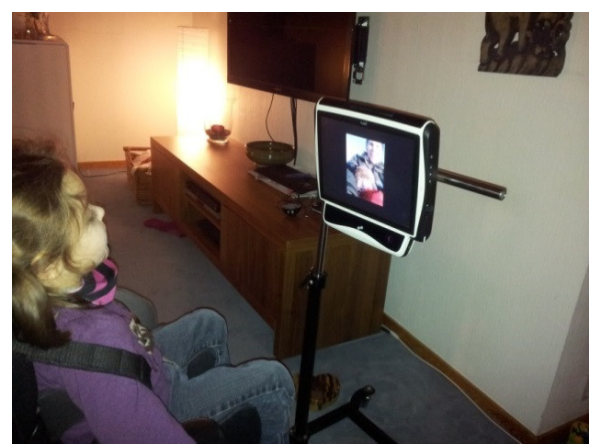

Figure 1. A child gaze controlling a video in her gaze-based AT, C12.

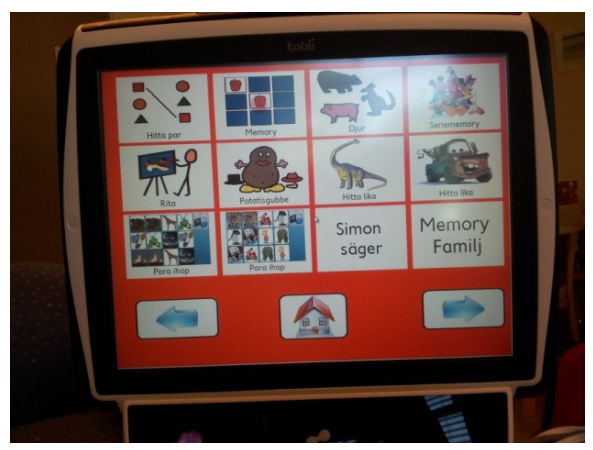

Figure 2. Example of a page with play activities.

\section{Services}

The services in the GAT intervention were based on the same key elements (see Table 3), components and collaborative consultation (Villeneuve, 2009) as was used in the pilot study. The services were provided by the MPC team over a period of 14 days, spread over 9-10 months. The purpose of the services was to optimise implementation and children's use of gaze-based AT. To enable performance of daily activities with gaze-based AT the interaction between the child, the specific activities, the adaptation of the gaze-based AT software and the key persons in the child's environment was considered, in accordance with the HAAT model (Cook \& Polar, 2015). Therefore, parents and all key persons (i.e. those who played a role in the child's use of gaze-based AT in daily life) were involved in joint goal-setting, planning and jointly reviewing progress in using gaze-based AT at home and at school. The intervention was implemented in groups of 2-5 children at the same time. Services provided at a group level included course days for parents, teachers and children respectively. This was combined with individual meetings (5-14 individuals participated for each child) and support for each child. Meetings were most often conducted at the child's school. During the services, parents and teachers were encouraged to play an active role in adapting the gaze-based AT to the children's needs over time. Table 4 gives an overview of steps A-C, showing all components over time in the intervention. At least two professionals participated from the MPC team, and provided services during each component in the intervention. 
Step $A$ in the intervention programme started with introductory days with education for key persons, initial adaptations of gaze-based AT by the MPC team in collaboration with key persons, and training for the child in eye gaze control and in using gaze-based AT. The planning meeting focused on the children's motivation for activities, and each child's prerequisites (e.g. gaze control skills, communication). Problems the children faced in participating in daily activities were also identified and prioritised (e.g. not being able to comment or answer questions during circle time at school), goals for gaze-based AT usage in daily activities were formulated collaboratively and gaze-based AT strategies were developed (e.g. who is responsible for the goal, activities for reaching the goal and how to support the child in undertaking the activity). After the planning meeting a goal-planning document was developed by the MPC team to ensure a shared focus in the goals. This was delivered to everyone who had participated in the planning meeting.

Step $B$ consisted of course days for teachers and parents (teachers meeting teachers; parents meeting parents). During the follow meeting 1, the goals in the goal-planning document were evaluated collaboratively, and strategies were revised if necessary.

Step $C$ consisted of a course day for children, and one for teachers. During the former, the children played games and music together by using their gaze-based AT. The aim was for them to practise using the system and to have a positive experience with it. Step $\mathrm{C}$ also included follow up meeting 2 .

Individual support was provided by the MPC team when required, and could be initiated by parents, teachers or other key persons, as well as by MPC team members. This consisted of home and/or school visits on five different occasions by members of the MPC team to provide direct or indirect support to the child, 
parents and/or teacher and assistants, such as adapting the software, guiding them to use gaze-based AT in daily activities, or supporting them with gaze control.

All key persons were trained to support the children in learning to use gaze control in the new activities at school and at home. This support included guiding children in terms of where to look on the screen, or pointing at the place on the screen where they needed to look. The support was then reduced over time as children became more independent in the activity, until they could perform it by themselves or handle the gaze-based AT without support from another person. 
Table 4. Description of format and content in the GAT intervention

\begin{tabular}{|c|c|c|c|}
\hline Steps & $\begin{array}{l}\text { Type of } \\
\text { meeting }\end{array}$ & $\begin{array}{c}\text { Key person receivers and } \\
\text { the child }\end{array}$ & Content \\
\hline \multicolumn{4}{|c|}{ Step A (0-1 month) } \\
\hline $\begin{array}{l}\text { Introduction } \\
\text { Days } 1 \text { and } 2\end{array}$ & : & $\begin{array}{l}\text { Parents, teachers, assistants, } \\
\text { child }\end{array}$ & $\begin{array}{l}\text {-Education in the software program and in } \\
\text { gaze calibration, and how to handle the gaze- } \\
\text { based AT for key persons } \\
\text {-Child prerequisites and motivation for use } \\
\text { - Initial adaptation of the gaze-based AT } \\
\text {-Initial training for the child }\end{array}$ \\
\hline $\begin{array}{l}\text { Planning } \\
\text { meeting } \\
\text { Day } 3(2 \mathrm{~h})\end{array}$ & : & $\begin{array}{llr}\text { Parents, } & \text { teachers, assistants, } \\
\text { local } & \text { paediatric team } \\
\text { members, AT centre members }\end{array}$ & $\begin{array}{l}\text {-Child prerequisites and motivation for use } \\
\text {-Family's priorities for the child's use of } \\
\text { gaze-based AT } \\
\text {-Prioritising participatory problems } \\
\text {-Formulating and grading goals, and } \\
\text { developing gaze-based AT strategies }\end{array}$ \\
\hline
\end{tabular}

\begin{tabular}{|c|c|c|c|}
\hline \multicolumn{4}{|c|}{ Step B (1-5 months) } \\
\hline $\begin{array}{l}\text { Course day } \\
\text { (school) } \\
\text { Day } 4(6 \mathrm{~h})\end{array}$ & $\overparen{3}$ & Teachers, assistants & \multirow{2}{*}{$\begin{array}{l}\text {-Demonstration of child's gaze-based AT use } \\
\text { by key persons } \\
\text {-Exchange of experiences } \\
\text {-Solving problems with gaze-based AT } \\
\text { adaptations } \\
\text { - Adaptation of gaze-based AT by key persons } \\
\text { from formulated goals, own work }\end{array}$} \\
\hline $\begin{array}{l}\text { Course day } \\
\text { (home) } \\
\text { Day } 5(6 \mathrm{~h})\end{array}$ & $\stackrel{0}{0}$ & Parents, assistants & \\
\hline $\begin{array}{l}\text { Follow up } \\
\text { meeting } 1 \\
\text { Day } 6(2 \mathrm{~h})\end{array}$ & 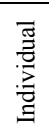 & $\begin{array}{l}\text { Parents, teachers, assistants, } \\
\text { local paediatric team member, } \\
\text { AT centre member }\end{array}$ & $\begin{array}{l}\text {-Discussing actual use of gaze-based AT } \\
\text {-Child prerequisites and motivation for use } \\
\text {-Evaluation of goals }\end{array}$ \\
\hline \multicolumn{4}{|c|}{ Step C (5-10 months) } \\
\hline $\begin{array}{l}\text { Course day } \\
\text { (school) } \\
\text { Day } 7 \\
\text { ( } 1 / 2 \text { day) }\end{array}$ & $\underset{0}{0}$ & Teachers, assistants & $\begin{array}{l}\text {-Exchange of experiences } \\
\text {-Solving problems with gaze-based AT } \\
\text { adaptations } \\
\text {-Adaptation of gaze-based AT by key persons } \\
\text { from formulated goals, own work }\end{array}$ \\
\hline $\begin{array}{l}\text { Child course } \\
\text { Day } 8(4 \mathrm{~h})\end{array}$ & $\stackrel{\Xi}{0}$ & $\begin{array}{llll}\text { Children with parents or } \\
\text { assistants }\end{array}$ & $\begin{array}{l}\text {-Children meeting and using the gaze-based } \\
\text { AT in a group activity, such as playing games } \\
\text { or playing music together }\end{array}$ \\
\hline $\begin{array}{l}\text { Follow up } \\
\text { meeting } 2 \\
\text { Day } 9 \text { ( } 2 \mathrm{~h})\end{array}$ & $\underset{\Xi}{\stackrel{Z}{Z}}$ & $\begin{array}{l}\text { Parents, teachers, assistants, } \\
\text { local paediatric team member, } \\
\text { AT centre member }\end{array}$ & $\begin{array}{l}\text {-Discussing actual use of gaze-based AT } \\
\text {-Child prerequisites and motivation for use } \\
\text {-Evaluation of goals } \\
\text {-Documentation, the goal-planning document }\end{array}$ \\
\hline \multicolumn{4}{|c|}{ Individual support (during step $A-C$ ) } \\
\hline $\begin{array}{l}5 \text { occasions } \\
\text { Days } 10 \text { to } 14 \\
\text { (2-4 h/day) }\end{array}$ & 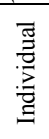 & $\begin{array}{l}\text { Parents, assistants, teachers, } \\
\text { child }\end{array}$ & $\begin{array}{l}\text {-Direct and/or indirect support at home and/or } \\
\text { school (e.g. technical, pedagogic, eye gaze } \\
\text { control) }\end{array}$ \\
\hline
\end{tabular}




\section{OUTCOME MEASUREMENT}

The outcome variables for the use of gaze-based AT in children with complex needs focused on the activities (type of activity, extent and duration) (Study II), goal attainment in prioritised activities (Study II), parents' satisfaction with the device and with services (Study II), and the child's gaze control skills (eye gaze performance) (Study III). The instruments for data collection in Studies II-III are shown in Table 5.

Table 5. Data collection in Studies II-III.

\begin{tabular}{lllcc}
\hline Study & Data collection & Usability & Objective & $\begin{array}{c}\text { Data } \\
\text { collected }\end{array}$ \\
\hline II & $\begin{array}{l}\text { Computer usage-diary } \\
\text { school }\end{array}$ & AT usage & $\begin{array}{c}\text { Activities } \\
\text { (type and extent) }\end{array}$ & 14 days \\
II & $\begin{array}{l}\text { Computer-usage diary } \\
\text { leisure }\end{array}$ & AT usage & $\begin{array}{c}\text { Activities } \\
\text { (type and extent) }\end{array}$ & 14 days \\
II & $\begin{array}{l}\text { Goal Attainment } \\
\text { Scaling }\end{array}$ & Effectiveness & Goal achievement & $\mathrm{X}$ \\
II & Quest 2.0 & Satisfaction & Parents' satisfaction & $\mathrm{X}$ \\
III & Compass 2.0 & Efficiency & $\begin{array}{c}\text { Time on task } \\
\text { and accuracy }\end{array}$ & $\mathrm{X}$ \\
\hline
\end{tabular}

\section{Study I - the pilot study}

A computer-usage diary and Goal Attainment Scaling (Kiresuk, Smith \& Cardillo, 1994) were tested in the pilot study, and these measures are described in more detail in the outcome measurements for Studies II-III.

The computer-usage diary was constructed with three questions to measure variables of daily AT usage. This was then tested in the pilot study (Study I). The three questions were in line with earlier research (Lenker \& Paquet, 2004; Lenker, Scherer, Fuhrer, Jutai, \& DeRuyter, 2005): frequency of use per day, 
duration of use per day and types of AT activity each day. For a period of 14 days, the students entered information in their diary of their computer use each day. The results from the pilot study showed that one of the questions, frequency of use each day, yielded less information on computer use. The computer-usage diary was therefore revised after Study I by excluding the frequency question.

Goal Attainment Scaling (GAS) (Kiresuk et al., 1994) was tested to determine how appropriate it was to set goals for performing activities with computer in the school context. Performance levels were graded in terms of the expected outcome. The students themselves evaluated whether goals had been achieved. Two questions were asked in the follow-up stage to assess teachers' opinions of setting goals and using GAS. The first asked whether they agreed with the students' evaluation of the goals, in other words, whether they had observed the same levels of performance in the educational tasks at the end of the intervention as the students had noted in their GAS ratings. Teachers were also asked during the follow-up stage whether they would use goal setting in computer use with other students. Teachers responded to the questions by e-mail or phone call.

Study I also involved the Psychosocial Impact of Assistive Devices Scale (PIADS) (Jutai, \& Day, 2002), used to measure the effect of AT on students' perceived functional independence, well-being and quality of life at school. The instrument has three scales; Competence (eight items), Adaptability (six items) and Self-esteem (eight items). There are 26 items, scoring from -3 (maximum negative impact) to +3 (maximum positive impact). The instrument has shown good construct validity, good test-retest reliability (0.77 to 0.85$)$ and good internal consistency (Cronbach's values 0.87 to 0.95 in the original English version, and 0.86 to 0.95 in the Swedish translated version) (Jutai \& Day, 2002; Pettersson, Ahlström, \& Törnquist, 2007). The instrument was used to assess whether the basic components in the intervention had any effect on students' independence and well-being at school, in any direction. This instrument was not used in Study II due to the children's complex needs. 
A teacher questionnaire was also used at baseline in Study I. It was constructed for the study and consisted of (a) two questions: teachers' frequency of computer use during lessons (1 "Never" to 5 "Each day") and teachers' satisfaction with their own computer use in the educational setting (1 "Not at all" to 5 "Very much"), and (b) three statements concerning teachers' perceptions of computer use in an educational setting, such as their perception of whether they had received relevant information about the student, and about students' computer use. The statements were graded with "Don't agree", "Partly agree", "Agree" or "Don't know".

\section{Studies II-III}

The computer-usage diaries were used to measure variables for activities with gaze-based AT (Study II). Over a period of 14 days, parents, assistants and teachers observed and documented the daily use of gaze-based AT in a computerusage diary at home, and another diary at school. The following were noted each day: 1) types of computer activity: one or more of the pre-defined activities $(n=10$ in school computer diary, e.g. talking to someone, playing games, skills training) or by adding their own activities, 2) duration of use (in minutes) per activity, noted through individual responses, estimated after each activity during the day. The data obtained from computer-usage diaries in Study II were used as reference data in Study III.

Goal Attainment Scaling (GAS) (Kiresuk et al., 1994) was used in Study II, collaboratively with key persons, to formulate and grade goals for computer use in daily activities at baseline. It was also used to evaluate these goals longitudinally. GAS has a five-point scale, as shown in Table 6. At baseline, the current individual level was formulated at level -2. GAS can detect clinicallyrelevant change with good responsiveness (Sakzewski, Boyd, \& Ziviani, 2007; Steenbeek, Gorter, Ketelaar, Galama, \& Lindeman, 2011) and content validity, by determining goals that represent important progress (Palisano, 1993). 
Table 6. Description of GAS scoring and levels.

\begin{tabular}{cl}
\hline GAS score & Description of level \\
\hline 2 & Much more than expected \\
1 & More than expected \\
0 & Expected \\
-1 & Less than expected \\
-2 & Much less than expected \\
\hline
\end{tabular}

In Study II, was The Quebec User Evaluation of Satisfaction with Assistive Technology (QUEST 2.0) (Demers, Weiss-Lambrou, \& Ska, 2002) used to measure parents' satisfaction with the gaze-based AT as a device ( 8 items), and with the services (4 items) related to the gaze-based AT. Quest 2.0 was used at post intervention and at follow up. Regarding the scoring of services at post intervention, were parents instructed to think of the service in the GAT intervention. Then, at follow up they were instructed to think of the traditional services (after the end of service in the GAT intervention). Quest has a five point ordinal scale (1-5), from "Very satisfied" to "Not at all satisfied". The instrument shows good interval consistency and validity, and good test-retest stability (0.820.91), (Demers et al., 2002).

To measure children's eye gaze performance in study III, were the Aim test used in the instrument Compass 2.0 Software for Access Assessment (Koester, Simpson, Spaeth, \& LoPresti, 2007). The instrument measures children's eye gaze control skills in controlling the mouse pointer during computer interaction with the gaze-based AT. Twelve targets (100x100 pixels) were randomly presented one at a time on the screen, with blank periods of two seconds in between, and the children were encouraged to fixate with eye gaze on the target on screen until it disappeared (required fixation for one second). Failure to fixate the target within 30 seconds resulted in a missed target. This test was repeated three times at each occasion. The test measure's the time on task and accuracy during performance. Time on task is the total time from when the target is 
presented to when the child has selected the target. Accuracy is measured as a selected or a missed target. The Aim test in Compass has demonstrated high testretest reliability (intraclass correlation coefficient 0.98), good internal consistency (Cronbach $\alpha$ of 0.77) (Koester et al., 2007), and high construct validity (Koester, LoPresti, \& Simpson, 2011). Figure 3 shows the screen display of Compass.

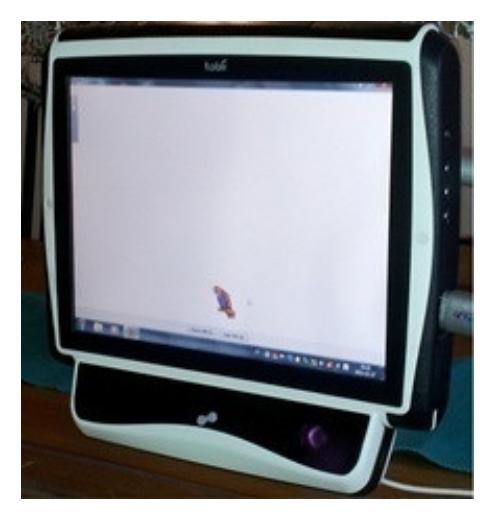

Figure 3. A view of the Aim test in Compass 2.0, which was used to measure outcomes in Study III.

\section{INTERVIEWS}

\section{Study IV}

In Study IV, semi-structured interviews were held with parents, to understand their experiences of their children's gaze-based AT use in daily life. Depending on parents' preferences, individual interviews or joint interviews (both parents) were conducted (Polit \& Beck, 2008). According to Gadamer (2004), the ontological structure of understanding is that it undergoes constant movement. New experiences over time present constant opportunities to develop our understanding. To better understand how parents' experiences unfold over time, parents were therefore interviewed twice. The first interview was conducted 
when the children were just beginning to use gaze-based AT at home, and again about one year later. The interviews consisted of five open-ended questions covering: (a) how the child has been using computer devices up to now, (b) thoughts about the child starting to use the gaze-based AT (c) how the child has been using her gaze-based AT (d) what parents think it meant to the child to use the gaze-based AT, (e) what it meant to the parents that the child use the gazebased AT, and (f) thoughts about the child using gaze-based AT in future. The first two questions were the focus of Interview 1, although parents also talked about their thoughts on future use at the first interview. Probes such as, 'Can you give an example of that?' were used during interviews.

\section{PROCEDURE}

\section{Study I}

At baseline, all students had access to a computer at school. Students and teachers were informed about the study by telephone contact with the researcher. The time points for data collection in this pilot study were at baseline, and then at two months (post-intervention) and four months (follow-up) after the AT intervention had ended. The time points were set up to evaluate outcomes within the same school year. At baseline, data were collected from students by giving them computer-usage diaries, and by telephone contact with the researcher for administration of PIADS. At baseline, teachers also answered the teacher questionnaire. After data collection at baseline, the AT intervention began with the group course day for teachers (semester one in the school year), followed by a planning meeting within the next three months. Goals were set using GAS at the planning meeting. After the intervention, data were collected by telephone contact with students for evaluation of GAS (post-intervention and follow-up) and for administration of PIADS (post-intervention and at follow-up). At follow 
up, computer-usage diaries were again distributed to students for documentation over a period of 14 days at follow-up, and teachers were asked about setting goals and about students' evaluation of goals.

\section{Studies II-IV}

\section{Baseline}

Time points for data collection in Studies II and III (T1-T4) are shown in Figure 4. At baseline, three children already had access to gaze-based AT, and seven were provided with it at baseline (Studies II-IV). The children's parents were informed about the studies at a meeting with one person from the research group at the regional paediatric rehabilitation centre. Computer-usage diaries were then distributed to parents and teachers (Study II), and they documented their children's daily use of the AT over a period of 14 days; the teachers monitored daily usage at school and the parents monitored it at home. At baseline, children's eye gaze performance were also assessed with Compass 2.0 (Study III), and parents were interviewed (Study IV) at the regional paediatric rehabilitation centre or at their home, according to their preference.

\section{Intervention}

The GAT intervention began with introduction days, followed by planning and follow-up meetings, course days and individualised support. It lasted in total between nine and ten months. During the intervention, GAS was administered at the planning meeting and during follow-up meetings (Study II), and Compass assessments were undertaken at T2 (Study III).

\section{Post-intervention}

At post-intervention, computer-usage diaries were distributed once again to teachers and parents (Study II), who documented usage over a period of 14 days. 
In addition, parents completed Quest 2.0 (Study II), and eye gaze performance was assessed using Compass (Study III).

The second interview with parents (Study IV) was conducted about one year after the first interview with them at baseline.

\section{Follow-up}

Computer-usage diaries were again completed by teachers and parents at T4 (Study II). Parents completed Quest 2.0 for the period between the end of services in the GAT intervention and the follow-up (Study II). Each child's eye gaze performance was also assessed at T4 using Compass.

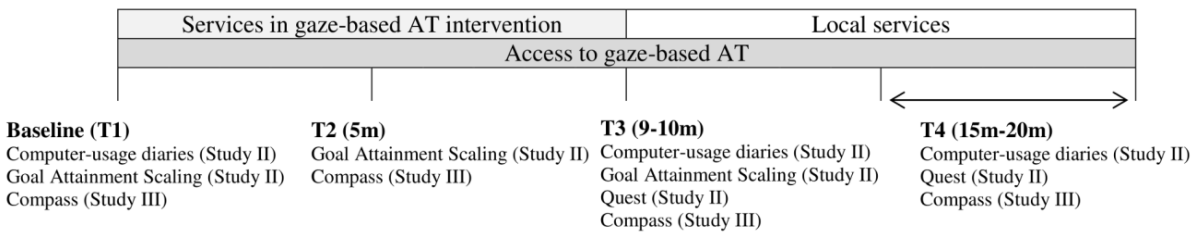

Figure 4. Time points for data collection in Studies II-III. Children had access to services from LPR centre (technical support, education on gaze-based AT) between T3 and T4.

\section{Compass assessment situation}

In Study III, the children's eye gaze performance were assessed using Compass 2.0 in a standardised environment in their own home, at school or at the regional paediatric rehabilitation centre. The child's position in relation to the gaze-based AT was adjusted for optimal height and horizontal distance between eyes and screen by using the track-status viewer in the gaze-based AT, resulting in distances of 55-59 $\mathrm{cm}$. Before assessment at each time point, individual gaze calibration was performed when the child looked at a few pre-defined calibration points to allow the eye camera in the gaze-based AT to detect the best user profile. One initial trial was then performed at each assessment, and all children 
showed that they were able to look at targets accurately on the screen. Thereafter, three tests were performed, offering breaks in between if needed. Children were encouraged to fixate their eye gaze on the targets as quickly as possible.

\section{DATA ANALYSIS}

\section{Study I}

Data from computer-usage diaries were calculated for each school diary for each time point for the following variables: duration ( $\mathrm{min} /$ day, mean), percentage of user days (\%), frequency of use per day (mean), and number of activities per day. Missing days were excluded before calculation of variables (17/420). To determine differences over time, the Wilcoxon signed rank test was used between baseline and follow-up in AT usage variables. Goals formulated with GAS were evaluated at group level in Study I. Differences in GAS scoring, as well as in PIADS over time, were analysed with Friedman's analysis of variance for all three time points, and thereafter with the Wilcoxon signed rank test to determine differences between time points. Non-parametric analysis was chosen because of the qualitative variables in these measurements and because of the small sample (Kirkwood \& Sterne, 2003).

\section{Studies II-III}

In Study II, data from computer-usage diaries were evaluated at an individual level, and calculated for school and home diary together for each time point. The variables were as follows: duration ( $\mathrm{min} /$ day) with sum of minutes for each day, percentage of user days (\%), number of activities per day and number of activities in total for each time point (activity repertoire) (Study II). Missing days were excluded before calculating variables (25/420). Graphs were constructed, in which duration and number of activities/day were presented day by day for each child at each time point. Changes in data patterns across time points in terms of duration and number of activities/day were analysed visually by searching for 
changes in levels between phases and changes in trends within phases (Ottenbacher, 1986). The percentage of days for all time points was presented in graphs for each child.

Goals formulated with GAS were analysed at an individual level in Study II. Each goal was evaluated for each child as: no improvement (scoring -2), improved (scoring -1 ) or attained (scoring $0,+1$ or +2 ). Goals for all children were grouped into categories which described the content of the goals.

For data on parents' satisfaction from Quest 2.0, median and interquartile range were calculated for each scale (Device Scale, Service Scale, Total Scale) at postintervention and at follow-up in Study II. Parents' scores were also analysed at the level of each item (Demers, Weiss-Lambrou, \& Ska, 1996) by grouping scores as satisfied (scoring 4 and 5) and less satisfied (scoring 1, 2 and 3).

In Study III, data from Compass were analysed at group level. The random effects regression model was used for time on task, and the general estimation equation model (GEE) was used for accuracy (Kirkwood \& Sterne, 2003). Both models take into account that the repeated measurements made in each child may correlate and adjust for the varying number of occasions between children. Children were divided into three age groups: 1-7 years (four children), 8-9 years (three children) and 10-15 years (three children). GEE was used to test accuracy (categorized as selected or missed), as a function of the independent variables time point (4 time points), age group (3 groups), test number (1-3), target number in test (1-12), target serial number in time point (1-36) and distance of target from mouse cursor ( 3 distances). To reduce skewness in the time on task data, $\log$ transformation was performed before using a random effects regression model to identify factors associated with time on task. The child was set as the random effect, thus taking into account that repeated measurements within a child could correlate with each other. Time on task was tested against the same 
independent variables as used for accuracy (age group, test number, target number in test, target serial number in time point, distance from target to mouse cursor).

\section{Study IV}

The qualitative analysis of parents' experiences was guided by hermeneutical interpretation (Gadamer, 2004). The recorded interviews were transcribed verbatim. At first, all transcripts were read and reread several times to get a sense of the whole (Gadamer, 2004). To develop an understanding of parents' experiences, these readings were done for each transcript, both transcripts with the same participant (Interviews 1 and 2), and then across all transcripts. Next, to find participants' perspectives, sentences or parts of the text which described their experiences of their children's use of gaze-based AT were extracted from the transcripts. In order to remain open-minded during this process, the intention was to search for things that surprised or areas which had not previously been considered before. The text was then interpreted, and this process was guided by a dialogue with the text; questions were posed to the text and answers sought. According to Gadamer (2004), posing questions opens the way for possible meanings. An example of a question was, 'What aspects of children's use of gaze-based AT seem important to parents? Following this, the text was searched for similarities and differences in how experiences were interpreted. Similarities were brought together in six sub-clusters and validated against the descriptions of experiences. Then similar and different meanings were explored, and similarities were brought together in three clusters. These were then validated against descriptions of experiences and against sub-clusters. An outstanding finding was that hope emerged in parents' descriptions of their children's use of gaze-based AT. In order to deepen the understanding of the clusters and sub-clusters, they were therefore explored further by considering Mattingly's research (2010) on creation of hope in parents of children with severe conditions. This process 
involved moving back and forth between descriptions, sub-clusters, clusters and Mattingly's (2010) research of hope, until an overall understanding emerged which integrated all parts with the whole and vice versa. The overall process of analysis involved moving back and forth between 'the steps' of searching for the whole through reading the text, finding the parts of the text which described the participants' perspectives, and revising sub-clusters, clusters and overall understanding.

Throughout the process of data analysis, co-authors carefully discussed and peerexamined nuances in participants' experiences and rival interpretations (Patton, 2002).

According to Gadamer (2004), for an interpretation to be valid, it must be the most suitable and reliable one in the given situation. The interpreters, i.e. the researchers, are part of the situation by belonging to its history and tradition. Hermeneutical interpretation therefore requires respect for tradition and its power (Gadamer, 2004). To find a valid meaning, interpreters must be open to tradition and what it can tell them. Validity was checked by allowing participants' descriptions of their experiences, the emerging meanings and overall understanding to challenge the author's pre-understanding during analyses, as well as by maintaining a dialogue with co-authors about the pre-understanding and emerging ideas. All co-authors participated in reading the transcripts, and also in analysing and questioning emerging interpretations. The author lifted phrases and extracts from the transcripts, and these were peer-examined by the co-authors to validate that descriptions of experiences were related to the children's use of gaze-based AT, and that none of these descriptions of experiences were excluded.

A reflexive diary was used as an essential tool in the process, to highlight thoughts and ideas which may have been taken for granted, or which may have 
been more anchored in the rehabilitation context or in the first author's own experiences. Author and co-authors peer-examined interpretations and colleagues were also asked to do this during the research process (Patton, 2002).

\section{ETHICAL CONSIDERATIONS}

Permission to conduct the studies in this thesis was obtained from the Regional Ethical Review Board in Stockholm (2008/726-31/5) for Study I, and from the Regional Ethical Review Board in Uppsala, Sweden (2010/316) for Studies II IV.

Students or parents (when child age $<18$ ) in Study 1 received written information by post. The cover letter to parents also contained information directed to the student. Thereafter, oral information was provided to students and parents through telephone contact. Students, or both parents and students (if student age $<18$ ), gave oral informed consent to the study. When they had agreed to participate, teachers and school principals were sent written information about the study by post. Teachers were then contacted by phone, and gave their oral consent to participate. In Studies II-IV, parents received written information about the studies by post, and thereafter a researcher met the parents at the regional paediatric rehabilitation centre, where they were given oral information. Both parents of each child gave their written, informed consent to participate with their child in the studies. Teachers and school principals were then provided with written information about the studies. Teachers in Studies II-III were also contacted by telephone and given oral information, and teachers gave oral, informed consent to participate in the studies. School principals in Study I and Studies II-III were provided with contact details with the written information, and were encouraged to contact the research group if they had any questions or if they decided not to consent to the research. 
All participants (Studies I-IV) were informed that they could withdraw from the studies at any time without giving any explanation. Given the longitudinal design of the research involving children with complex needs (Studies II-IV), with research activities taking place over time, parents and teachers were informed that they could withdraw from the research at any time, without having any effect on the services the child was receiving for the gaze-based AT.

An ethical dilemma in studying children with complex needs who could not speak (Studies II-IV) was that they constituted a vulnerable group because of their impairments and special needs (Graham, Powell, Taylor, Anderson, \& Fitzgerald, 2013). Their severe communication difficulties made it difficult for them to give informed consent to the research. Therefore, parents were used as proxies for these children, and spoke on their behalf in terms of deciding whether to participate in the research project. An information letter with pictures was included in the written information to parents, to be used for informing children when possible. Parents were recommended to use this letter to inform their child about the research activities (e.g. visits at school), if it was appropriate to the child's age and understanding. Another dilemma is that children with complex needs are exposed to health-related issues, which may affect their ability to participate in longitudinal research. For example, two children in this research had sickness periods that caused them to be absent from school for a time during the GAT intervention. Despite this, they both could continue to participate in the GAT intervention. Long sickness periods and hospital stays may be one reason why vulnerable groups of children are often excluded, and are therefore underresearched. Graham et al. (2013) highlight the fact that excluding vulnerable groups of children from research also means they are excluded from the potential benefits of research and this contributes to inequity and injustice. In Studies IIIV, the researcher needed to contact parents, teachers and the MPC team, and some flexibility was necessary to ensure that all the required data could be collected. 
It is likely to be especially challenging to be a parent of one of these children (Studies II-IV). They have a variety of responsibilities in addition to the normal responsibilities of a parent, such as long-term contact with professionals in different organisations in order to manage their child's impairments on a daily basis. It was a challenge to collect data from parents within specific time periods, as the parents sometimes did not return the data, although it had been completed. The researcher therefore maintained telephone contact with all parents throughout the research project to ensure that data were returned. Sometimes the researcher met parents while they were with the GAT intervention services, to suit the parents better and to enable them to return completed data. Another issue for the children included in study II-III was that they not had the ability to leave a situation they do not like (Graham et al., 2013), and alongside communication difficulties these children may have problems expressing this to a researcher. Therefore, when the researcher collected data from children in Study III, it was important that significant others took part (a parent, assistant or teacher), who knew the child's way of communicating well, to ensure right interpretation of the child's communication attempts during assessments with the children. 


\section{RESULTS}

\section{STUDY I}

The findings in study I showed that at baseline, most teachers stated they lacked information about students' impairments and that they needed access to services to support students' use of computer as AT in educational tasks.

Study I also showed that a computer-usage diary could be used on an individual level to evaluate computer use variables over time. The results indicated individual positive changes, with 12 students (12/15) increasing their percentage of days of computer use in at least one activity. As they increased in their use of different activities, no significant improvements could be found on a group level for any of the activities in this pilot study. No significant differences over time on a group level were found in regard to the variables of computer use.

Furthermore, study I also showed that GAS could be used to set up and evaluate goals related to performing educational tasks with computer, and that most teachers $(15 / 16)$ found goal setting feasible to use in the school setting with students. All teachers agreed with their student's goal evaluation. The results also showed a significant improvement in the ratings of goals $(n=28)$ postintervention, and that the effect was maintained at follow-up (after four months). However, not all goals were improved, which is why the results suggested increasing the number of collaborative meetings between teachers and professionals delivering services in any future adaptation of the intervention.

The results also showed that students perceived a positive impact from computer use in educational tasks at baseline, and there were no significant changes of this post-intervention or at follow-up. Thus, participating in the AT intervention did 
not compromise the perceived positive effect of a computer in educational tasks over time.

In summary, after the AT intervention, students showed some effectiveness in performing educational tasks with a computer, as they achieved goals for computer use. This shows that the AT intervention can improve the use of available computers in educational tasks in school.

\section{STUDIES II-IV}

\section{Activity repertoire}

Study II showed that all ten children included in the study performed computer activities both at post-intervention and at follow-up. The repertoire of computer activities had increased for seven children with higher values on a group level at follow-up compared to baseline $(n=10$, baseline median $=0.5$ activities, range $0-7$ activities, follow-up median $=4$ activities, range 1-6 activities).

One finding at follow-up was that talking to someone was the activity most children performed with the gaze-based AT (9/10) both at home (6/10) and at school (7/10). Another finding at follow-up was that the type of activity performed most frequently with gaze-based AT differed due to setting. At home, the activities most frequently performed among children $(n=8)$ were playing games, listening to music and/or looking at photos, and talking to someone. In school the most frequently performed activities among children $(n=8)$ were talking to someone, having skills training, or participating in circle time. At home, it was more likely that the younger children (ages 1-8) would use the gazebased AT for games, music and photos, whereas the oldest children most often used it to talk to someone (ages 15). 


\section{The use of gaze-based AT}

Study III also showed how the computer usage variables (duration, number of activities /day, percentage of days) changed over time when gaze-based AT was used in daily activities. The main findings were that after withdrawal of the services in the GAT intervention, there was ongoing autonomous use postintervention as well as at follow-up for all children included. For nine children $(9 / 10)$ a positive effect on computer use variables was found post-intervention compared to baseline, of which eight (8/10) showed a maintained positive effect at follow-up compared to baseline. The most common result found among children in the use of gaze-based AT over time was to have a positive and maintained effect in all three variables (6/10).

At follow-up, most children $(\mathrm{n}=7)$ performed activities with the gaze-based AT for between $63-100 \%$ of the days whereas three children had a somewhat lower percentage of days of usage (20-50\%). These three children used the gaze-based AT only at home or at school. At follow-up, the duration of use for all children ranged between 15-81 minutes per user day (median $40 \mathrm{~min} / \mathrm{user}$ day), and the number of activities per day ranged between one and six activities (median four activities/user day).

\section{Achievement of goals}

Study III showed that 58 goals were formulated for the children's use of gazebased AT in daily activities (3-9 goals/child, median 6). The study showed that all children attained goals, and most children (8/10) attained half to all goals post-intervention.

The results showed that $60 \%$ of the goals were achieved post-intervention, compared to $55 \%$ of the goals during intervention. Of the achieved goals, 13 were related to activities at home (13/21 achieved), and 22 were related to activities in school (22/37 achieved). Goals were achieved in all areas of use: 
communicating with others (10/20 achieved), interacting with others $(6 / 7$ achieved), learning to use gaze-based AT and achieve regular usage (10/13 achieved), making choices (6/12 achieved), and doing school tasks (3/6 achieved). Figure 6 shows goal achievement scoring for all 58 goals over time.

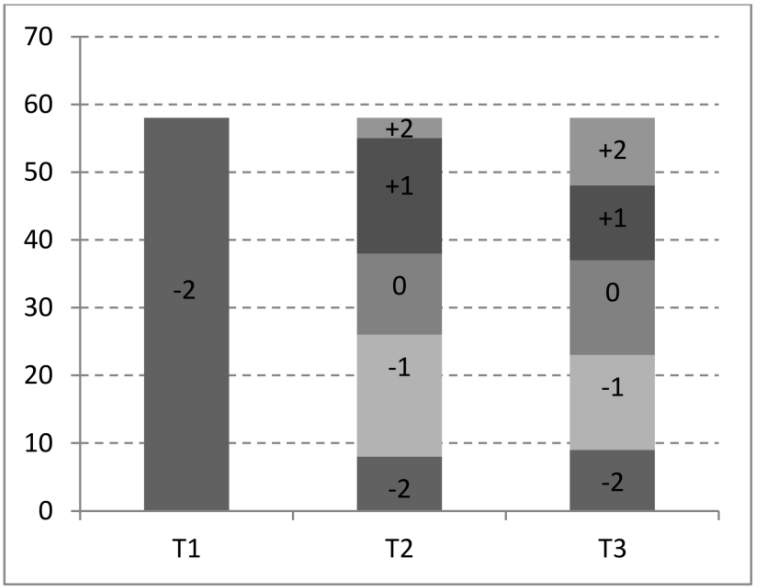

Figure 6. Achievement of goals $(\mathrm{n}=58)$ at the time points $\mathrm{T} 1-\mathrm{T} 3$, with no change $(-2)$, improved $(-1)$, and achieved $(0,+1$, and +2$)$. $\mathrm{T} 1$ baseline; T2 during intervention; T3 post-intervention.

\section{Parents' satisfaction of gaze-based AT}

Study II revealed that parents showed high satisfaction with both the device and with services post-intervention, with somewhat lower satisfaction at follow-up. Most parents were satisfied with the services (service delivery, professional services, repairs and services, and follow-up services) in the GAT intervention post-intervention. At follow-up, concerning the services provided after the GAT intervention, most parents were only satisfied with the professional services.

\section{Eye gaze performance}

In Study III, nine of ten children showed improvements of eye gaze performance over time for time on task and/or accuracy (time on task, seven children; 
accuracy, nine children). On a group level, the results of accuracy and time on task showed a learning curve with a main effect of time. Children were about three times more likely to be accurate at the last time point T4 (15-20 months) than at $\mathrm{T} 1$ (baseline) (OR 3.27, 95\% CI $=1.41-7.58, \mathrm{p}<0.01)$. No clinical relevant effect of age was found.

On an individual level, different learning curves were found among the children. Children with good to excellent improvements in accuracy (seven children), children with improved but with less accuracy (two children with alternating strabismus), and one child whose accuracy and time on task decreased over time (developed a treatment-resistant epilepsy during the study). The different learning curves found among children are shown in figure 6.

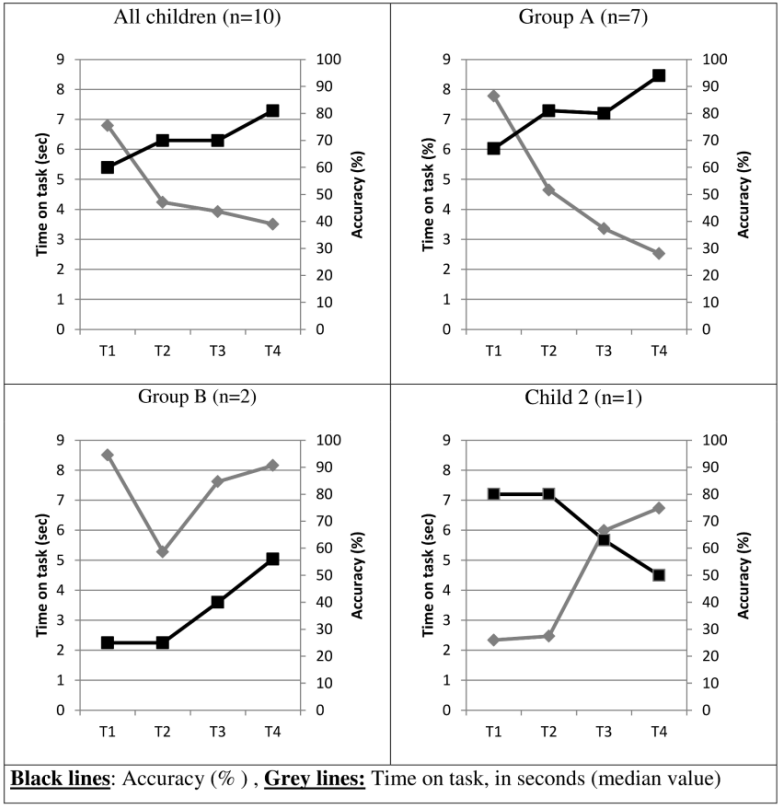

Figure 6. Learning curves for all children together, for group A (excellent improvements), group B (improvements in accuracy; alternative strabismus), and for child 2, the only child whose performance declined over time (developed epilepsy). 


\section{Hope of a better future - parents' experiences}

The analysis revealed three clusters concerning what children's gaze-based AT usage meant for parents: (a) children demonstrated agency, (b) opportunities for children to show personality and competencies, and (c) infinite possibilities of child development.

For the parents, children's gaze-based AT usage made a huge difference in daily life, since the children demonstrated agency by expressing basic needs and selfdetermination with the gaze-based AT, which they did not do before. The gazebased AT was a tool which provided the children with opportunities to take their own initiatives to express basic needs, and this meant that they sometimes expressed needs parents did not know about, such as the need to get help with pain, or the need to get help due to being thirsty. The gaze-based AT usage also meant that the children could perform activities independently, for example playing games or listening to music, which was not possible before. Through this, by doing the activities they themselves preferred, they showed their will and interests. For parents, children's gaze-based AT usage also meant that the children showed their personality and competencies. The analysis revealed that parents knew children's personality well, but through the use of gaze-based AT the personality became more visible. For example, they could show their sense of humour by teasing their parents or class-mates, or convey feelings such as 'I love you' to someone. The competencies also became more visible, through the different activities children performed, and highlighted the children as 'learners' since it became visible for parents that children learned new things by using the gaze-based AT.

For the parents, children's use of gaze-based AT also meant infinite possibilities for child development, as the gaze-based AT overcame some of the children's profound limitations. Finally, having found a tool the children could use on their own meant that parents saw a wide area of potential use for their children, with many further steps to take in learning new and challenging activities. This also 
meant the parents had feelings of great responsibility but also uncertainty about how to best support their children in taking the next steps with the gaze-based AT. The gap between children's abilities in the present situation and all potential possibilities needed to be handled by the parents.

The overall understanding of what children's gaze-based AT usage in daily life means to parents is that it shapes a hope of a better future for their children, a future in which the children may be able to use their inherent potential and develop in their own direction and gain influence in their future life. The gazebased AT usage uncovered the children's inherent potential and capabilities and brought out a shift in parents' views on their children, from being totally dependent and unable to control their own lives, to being able to do things on their own and express things that matter to them. 


\section{DISCUSSION}

\section{THE IMPACT OF ASSISTIVE TECHNOLOGY ON DAILY ACTIVITIES}

The main findings of this thesis is that gaze-based AT is a usable device for children with severe physical impairments without speech, and that the GAT intervention had a positive effect on children's daily activities and on children's gaze control skills.

The results revealed a positive impact on 1) opportunities to perform activities, 2) activity repertoire, 3) communication and social interactions, 4) selfdetermination, and 5) eye gaze control skills. These main findings will be discussed below.

\section{Performing activities}

The results (Studies II-IV) show that by using gaze-based AT, these children with complex needs performed activities at home and in school, something they were unable to do before. Hence, the gaze-based AT made a difference by providing children with opportunities they did not have before. A prerequisite for this is that the environment provides the child with opportunities and resources that enable activities to be performed (Kielhofner, 2008; Cook \& Polgar, 2015). For example, children with complex needs are dependent on assistance for the setting up of the gaze-based AT and with being positioned so they can use it. The child must also be provided with support and strategies from parents and teachers to learn to use the AT, and the AT software needs to be adapted to each child's individual needs (Cook \& Polgar, 2015). Children also need support when learning to perform new activities, support that can be reduced over time as they become more independent (Case-Smith \& O'Brien, 2010). Thus, the social 
environment had an important influence on these children's opportunities for using the gaze-based AT for activities (Studies II-IV).

\section{Increased activity repertoire}

The findings in this thesis demonstrated that the repertoire of computer activities increased with the gaze-based AT for most children, independent of age or cognitive level (Studies II, IV). These findings provide knowledge about which daily activities that can be performed by children with complex needs when using gaze-based AT. As mentioned earlier, most children had no previous experience of performing activities to relate to (Studies II, IV) and it can be assumed that they needed to develop new habits for performing activities with eye gaze control over longer time periods. One case-study of a child with complex needs also indicates that using gaze-based AT to perform different daily activities was something that evolved over time (Donegan, 2012). Based on an occupational perspective (Kielhofner, 2008) frequently use of gaze-based AT will lead to a tendency to do certain things over time, and thereby to the development of habits of performing certain activities, resulting in an activity repertoire. Familiar individuals that children most often interact with, e.g. parents and teachers, will have a direct influence on children's choice of activities and regular use of the AT, due to their own expectations, attitudes and knowledge of the AT (Cook \& Polgar, 2015). Therefore, both parents' satisfaction with the gaze-based AT and with services in the GAT intervention (Study II), as well as the hope that is shaped among parents for the children's future due to use of gaze-based AT (Study IV) may have had a positive influence on the children's maintained use over time.

The findings show that most children performed activities with gaze-based AT up to one hour per user day (Study II). The findings also indicate that parents experienced that using gaze-based AT could be tiresome for these children (Study IV) which can be one explanation why gaze-based AT was seldom used 
for more than one hour per user day. This is in line with research indicating that it may be tiresome to gaze control a computer; to fixate on targets, switching between looking to explore and making selections with eye gaze, and trying to avoid unintentional selections during eye gaze performance (Godijn \& Theeuwes, 2004; Majaranta \& Donegan, 2012; Stampe \& Reingold, 1995). Nevertheless, all children gained an activity repertoire which shows that gazebased AT was usable for the children in performing activities, even though it could be tiresome to use.

The maintained activity repertoire over time with gaze-based AT (Studies II-IV) indicates that the AT and the activities match children's skills, interests and needs for activities, and this match is suggested to be a prerequisite for maintained use of AT over time (Cook \& Polgar, 2015). An AT requires flexibility in allowing adaptation of the content in the AT so it can be used for different ages, in different settings and with different purposes (Cook \& Polgar, 2015), and this is specifically true for gaze-based AT. For example, changing the type of pictures, or the size, number and spacing between pictures on each page in the software allows matching of the user's gaze control skills, diverse cognitive levels and ages, to the demands of the prioritized activities, so that each child can benefit from AT use (Cook \& Polgar, 2015). This was done in the GAT intervention by professionals, parents and teachers, and resulted in between three to 25 pictures on each page with a variation of between 60 to 800 pictures in total at the end of the intervention (see method section). This indicates that the gazebased AT was adapted based on each child's different interests and needs.

The preferences and need for activities seemed to differ according to the children's ages, which was shown both in the activity repertoire and in achieved goals for the use of gaze-based AT (Study II). For example, younger children usually played games, and the older children usually communicated with others. Goals for gaze-based AT use also differed between children of different ages; for example, in school, gaze-based AT was used to do arithmetic by an older child, 
while a younger child used it to play music for classmates (Study II). The literature underscores that children's engagement in activities will change over their life span at different ages and with the child's development (Davis \& Polatajko, 2006). It is therefore likely that the activity repertoire of a gaze-based AT also will differ at different ages. Thus, a prerequisite for maintained use over time is that key persons in the social context understand children's interests and needs and adapt the use of the AT to these changing needs in daily life (Cook \& Polgar, 2015). The need of adapting the AT over time confirms the need for service delivery over an extended time period, for all involved, so they can gain the knowledge they need for autonomous use after withdrawal of services in the gaze-based AT intervention.

\section{Communication and social interactions}

The findings show that activities related to communication and interaction with others represented an important area of children's gaze-based AT use at home and in school (Studies II and IV). Talking with someone was the activity most children performed, and it was present in nine of the ten children's activity repertoires in school and/or at home (Study II). In addition, more than half of the attained goals at post intervention (19/35) focused on communication- and interaction-related activities, including performing activities together with classmates or siblings (e.g. playing a game or music) (Study II). The benefits of gaze-based AT for children's communication and interactions was also addressed in Study IV, in which parents perceived that the gaze-based AT provided their child with language to communicate. Communication is essential for all aspects of learning (Drager, Light, \& McNaughton, 2010) and researchers propose that children with severe physical impairments and communication difficulties are especially restricted in social relations (Beckung \& Hagberg, 2002; Majnemer et al., 2008; Raghavendra et al., 2012), experience few opportunities for communication, and have limited interaction with communication partners (Hewitt-Taylor, 2008; Light \& Drager, 2007; Raghavendra et al., 2011). The 
findings (Studies II, IV) on gaze-based AT usage focusing on communication and interactions with others are therefore important as they may give increased opportunities to participate in situations with other people. Potential positive benefits of communication on child development were also emphasized by parents in Study IV.

Moreover, the findings also show that children's use of gaze-based AT seems to meet different needs for communication among children. Expressing wants and needs, sharing information with others and developing social relations with other people are described as some of the most important purposes of communication that need to be addressed in AT for communication (Light \& McNaughton, 2012). These purposes seem to be in accordance with the findings related to children's communication and interaction (Studies II, IV), as children used gazebased AT for expressing their wants and needs, communicated and shared information with others in school and at home, expressed their feelings and humour, and became personal with other people. Thus, these findings indicate that using gaze-based AT seems to offer children of all ages (ages 1-15) opportunities to use gaze-based AT for several communication purposes. For example, the findings show that even the youngest child (1 year) used gaze-based AT to communicate and interact with a sibling and parents (Study II). Based on these findings and on research indicating the need to provide children with opportunities for communication as early as possible (Light \& Drager, 2007), children as young as one year may benefit from using gaze-based AT for communication and interactions.

\section{Self-determination}

Another finding was that children demonstrated agency when using the gazebased AT. This gave them opportunities to influence their situation by expressing basic needs, making their own choices, taking their own initiatives and showing their will through what they did and what they communicated via the gaze-based 
AT (Studies II, IV). The studies also demonstrated that children with complex needs could independently perform activities through eye gaze control (Studies II-IV), and mostly performed independently for the first time (Studies II, IV). Having a sense of control over the activity and choosing what to do entail a subjective feeling of influencing the situation (Law, 2002; Molin, 2004). In addition, being active and motivated in taking initiatives to perform activities represent self-determination (Ryan \& Deci, 2000). The findings indicate that setting up goals indirectly targeting self-determination (e.g. making choices, usage of self-selected activities) may lead to functional gains of selfdetermination in daily life for non-speaking children with severe physical impairments. Key persons in the child's social context therefore need to adapt the content of the software to allow the child to influence the situation in the child's important areas (Cook \& Polgar, 2015). This also implies that parents need to be closely involved in the decision-making process on goals for AT use during services in the intervention (Cook \& Polgar, 2015). The Convention on the Rights of the Child (United Nations, 1989) states that all children have the right to express their views freely in matters that affect them. Giving opportunities for self-determination is an important clinical implication as the findings show that the children were able to take initiatives to communicate and do things that influenced their situation by using the gaze-based AT (Studies II, IV).

Hence, the findings show that children demonstrated power over what to use the gaze-based AT for (Studies II, IV). Children's own decisions may highlight their own highly prioritized needs and motivation for use of gaze-based AT. These findings are suggested to indicate the 'useworthiness' (Eftring, 1999) of gazebased AT for children in that they show what gaze-based AT is worth using for from the children's view, and not only its usability. For example, the findings show that children communicated basic needs that parents did not know about, or sometimes played games although parents hoped for other usage (Study IV). Nevertheless, even if Study IV indicates useworthiness from the children's view, this is dependent on what it is possible to use the gaze-based AT for (Eftring, 
1999), and to what extent adaptations of activities made in the software (e.g. key persons' selection of pictures) match children's perceived high priority needs (Cook \& Polgar, 2015). It must be remembered that these adaptations both define and set the limits for children's opportunities for self-determination, as well as for all other activities, during the child's interaction with the gaze-based AT. This means, as stated previously, that key persons in services must pay attention to the content of the AT and adapt it to children's changing needs over time (Cook \& Polgar, 2015). Observing children's own prioritized use of gaze-based may inform key persons of important areas of use that need to be developed for the child.

In addition, the findings also indicate the useworthiness of gaze-based AT from the parents' perspective. Observing children's opportunities for selfdetermination made parents better understand their children's perceived needs, and this made the parents hope for a future in which the children would be able to influence their situation in a better way by using the gaze-based AT (Study IV). This in turn meant that the parents were willing to spend time on the GAT intervention and support the child in use of gaze-based AT at home. Research indicates that parents of children with physical impairments worry about their children's vulnerable future situation (Antle et al., 2008). The findings of this thesis indicate the useworthiness of gaze-based AT from the parents' perspective, as children's gaze-based AT usage made the parents shift in their view of their children and consider they might have possibilities to gain control over their lives in future (Study IV).

\section{Eye gaze control skills}

The findings show increased efficiency in eye gaze performance over time for children (Study III), which indicates that the children acquired gaze control skills. Research indicates the need for longitudinal designs to capture usability of other AT (Arthanat, Nochajski, Lenker, Bauer, \& Wu, 2009). Case studies 
involving individuals with profound impairments and the use of gaze-based AT indicate the need to practice eye gaze control skills for several months to become efficient in eye gaze control of a computer (Donegan, 2012; Donegan \& Oosthuizen, 2006). This was also the case among the children in this thesis. The findings show that the children needed up to 15-20 months of practicing gazebased AT in daily activities to become fluent in eye gaze performance during interaction with the gaze-based AT (Study III). The performance capacity depends both on the child's objective physical and mental abilities, as well as on subjective experience of performing activities (Kielhofner, 2008). Children's gaze control skills will therefore depend partly on their experience of exploring and performing activities with the gaze-based AT, which may explain the increased eye gaze performance over time.

Initially, the children were novice users of gaze-based AT, which means they had no or limited previous experience of this AT or of performing the tasks it was used for. By practicing and gaining experience of its use in daily activities the user will demonstrate a higher degree of skill during interaction with the AT (Cook \& Polgar, 2015) which was found in Study III. 'Learnability' is a term that can be used in relation to AT usability, and is defined as how easy the device is to learn for a novice user (Nielsen, 1993), which is relevant as the system needs to be able to learn to be usable. The results indicate a variation of learnability of gaze-based AT among these children, which is important to understand in clinical practice. For example, adapting content in software to achieve a better match between the demands of the activity (e.g. enlarging pictures) and skills (Cook \& Polgar, 2015) of children struggling with eye gaze control may increase accuracy and speed during the performance of activities.

The results also showed that children gained benefits from using gaze-based AT for activities in school and at home while they were still learning gaze control skills (Studies II, III). All children already showed some degree of effectiveness in achieving goals for gaze-based AT use at five months. At the same time point, 
all the children were still learning gaze control skills and no one had yet become fluent in eye gaze performance (Study III). These findings show that children learn skills and generalize skills for use in different settings at the same time. The finding stands in contrast to traditional ways of understanding skill learning as stage-specific, which for example implies the need to become fluent in skills before being able to generalize and use skills for activities in different settings (Kramer \& Hinojosa, 2009; Parker, Burns, McMaster, \& Shapiro, 2012). The findings in this thesis (Studies II and III) suggest that giving opportunities to children to learn eye gaze control skills by exploring performance of activities with gaze-based AT in daily activities may lead to functional gains from gazebased AT in daily life while still acquiring skills. Nielsen (1993) highlights that users normally start using an interface in everyday life as soon as they have acquired partial knowledge of it, instead of waiting to learn fully about the interface before making practical use of it. This can be referred to as exploratory learning (Nielsen, 1993). This thesis shows that explorative learning may be an approach that is usable even for children with complex needs when gaze-based AT is implemented in daily activities, assuming that services are provided to support the implementation process. Designing activities with the just right challenge (Case-Smith \& O'Brien, 2010) giving children opportunities to explore new activities with support from adults, and to perform daily activities they have become more independent in, allows children both to learn skills and also gain benefits from performing daily activities at home and in school (Kielhofner, 2008).

\section{Participation in home and school settings}

In summary, the findings in this thesis reveal, as already highlighted in the previous discussion, that the gaze-based AT was used by children for performing activities at home and in school (Studies II, IV), for communication and for social interactions with people (Studies II, IV), and for self-determination (Studies II, IV). All these points have been argued in the literature and by 
different researchers to be important aspects of participation (Almqvist \& Granlund, 2005; Arvidsson et al., 2015; Law, 2002; Molin, 2004; Pereira et al., 2010) (WHO, 2007). Studies II-IV showed that children acquired eye gaze control skills, which is one of the prerequisites of using gaze-based AT for activities and participation. For these non-speaking children with profound impairments the use of gaze-based AT together with having access to related services for 9-10 months enhanced participation for the children in their immediate environment. However, only a small sample is included in this thesis and the results therefore need to be interpreted carefully. The results indicating enhanced participation need to be investigated for a larger group of children in future research. Nevertheless, based on the findings, aspects of participation (performance of activities, communication and social interactions, selfdetermination) should be considered as potential outcomes during service delivery and planning of gaze-based AT for non-speaking children with profound impairments. In practise, this means that professionals need to guide parents and teachers with knowledge about how to adapt the software to match the needs of different aspects of participation for each child.

The findings in this thesis (Studies II-IV), with positive outcomes on activities and participation when using gaze-based AT, can be understood as children moving beyond onlooker participation and entering the form of special task participation, as described by Pereira et al. (2010). Using eye gaze control of AT to perform activities in their actual contexts, children contribute to activities, although in a different way than for example siblings and classmates. Pereira et al. (2010) found that participation included both performance characteristics and social context aspects, such as attitudes and understanding. An inclusive attitude among key persons in the social context is a prerequisite for AT use, since their acceptance and awareness of alternative ways of doing is needed (Cook \& Polgar, 2015) to allow for special task participation with gaze-based AT. As already highlighted, the social environment has a pervasive influence on the outcome of the dynamic interaction between the child, the AT and the activity 
(Cook \& Polgar, 2015), and therefore plays a considerable role in the findings of children's opportunities for activities and participation (Studies II, IV) when using gaze-based AT in school and at home.

\section{An occupational perspective on health}

From an occupational perspective (Kielhofner, 2008; Wilcock \& Hocking, 2015) and in line with the WHO (2007) conceptualisation of health, these results of children's new opportunities to perform activities, increased activity repertoire, increased communication and interaction as well as new opportunities for selfdetermination all together indicate that gaze-based AT usage provides opportunities for development and learning (Studies II-IV) and by that can promote health among children with complex needs.

Research describes children with severe physical impairments without speech as totally dependent on assistance in all everyday activities (Hewitt-Taylor, 2008; Østensjø et al., 2005), and as being involved in only a few activities, most of which are related to the home (Majnemer et al., 2008; Raghavendra et al., 2011; Thirumanickam et al., 2011). Based on the finding that gaze-based AT provided children with new opportunities in daily activities, and theoretical frameworks indicating that participating in daily activities has a positive impact on health (Kielhofner, 2008; WHO, 2007; Wilcock \& Hocking, 2015), a suggestion for future research is to investigate the relationship between children's performance of activities and health-related quality of life. In addition and even more important, a suggestion for health policy is to prioritize the opportunities to receive gaze-based AT for children with complex needs.

\section{IMPLEMENTING GAT INTERVENTION}

The gaze-based AT's positive impact on children's activities (Studies II-IV) indicates that parents and teachers gained resources, skills and knowledge from 
the GAT intervention. This allowed them to implement the developed strategies at home and in school to support children in achieving goals with gaze-based AT. This indicate that the GAT intervention had the effect of empowering parents and teachers to support autonomous use of gaze-based AT for children after withdrawal of the services. This was clear since all children had maintained use five to ten months after the end of the services in the GAT intervention. Other research has shown that parents and teachers cannot always maintain use of AT after withdrawal of services (Salminen et al., 2004) and that lack of support for the implementation process leads to an underutilized gaze-based AT for children with complex needs (van Niekerk \& Tönsing, 2014). The findings of this thesis suggest that combining individual support with collaborative meetings as suggested by Villenueve (2009) and course days that include both education and practical work (Anderson et al., 2013; Baxter et al., 2012), may be a good model of service delivery when implementing gaze-based AT for non-speaking children with severe physical impairments at home and in school.

Parents' high satisfaction with the gaze-based AT and with services in the GAT intervention (Study II) can be seen as a facilitator of the implementation process. Parents perceived the services in the GAT intervention to be of high quality. This satisfaction shows that the professionals succeeded in meeting parents' needs and expectations (Weiss-Lambrou, 2002). In addition, maintained use of the gazebased AT (Study II) and satisfaction with the gaze-based AT as a device (Study II), indicate that the AT is a good match for the user (Weiss-Lambrou, 2002). Parents' hope for a better future for the children, which was raised due to the children's gaze-based AT use (Study IV), is suggested also to support the implementation process. However, the findings also reveal that parents were less satisfied with services provided for the gaze-based AT for the period after the end of the intervention. This may suggest the need for follow-up services by professionals specializing in gaze-based AT. 
To implement the GAT intervention several issues in the institutional environment needed to be addressed (Cook \& Polgar, 2015). Policies that establish that children with complex needs are eligible to be provided with a gaze-based AT are needed, and they also need access to various professionals with knowledge of gaze-based AT. Furthermore, being prioritized (e.g. economic resources in the County Council) for referral to the GAT intervention is also needed. Providing AT to clients without providing them with services due to the costs of the implementation process has been shown to lead to 'costs' of abandonment (in one-third of cases) or under-utilization of ATs (Cook \& Polgar, 2015; Scherer, 2002). For children with severe physical impairments, underuse of different ATs and of gaze-based AT has been reported due to poor implementation processes (Chantry \& Dunford, 2010; Hoppestad, 2007; Raghavendra et al., 2012; van Niekerk \& Tönsing, 2014). There are also 'costs' due to lack of AT. McNaughton et al. (2008) found that parents perceived high costs due to the lack of AT for communication with their children, which led to missed communication opportunities with the child. In addition, when provided with an AT, high learning costs of the AT were also perceived among parents due to lack of services. The findings of this thesis increase the understanding of the potential impact of gaze-based AT on children's daily activities among these non-speaking children with severe physical impairments. Research on functional outcomes from AT use promotes a focus on social costs due to the benefits that may be gained from its use (Cook, 2009) rather than on what ATs are usually distributed to different user groups. Focusing on the benefits from the use of an AT, it can be seen as an equalizer of opportunities (Peterson \& Murray, 2006) for children with severe physical impairments. 


\section{CLINICAL IMPLICATIONS}

The outcomes for the non-speaking children with severe physical impairments in the present thesis suggest that the target group acquired sufficient gaze control skills to use gaze-based AT for daily activities in school and at home. A prerequisite for this is that they are provided with opportunities to use gaze-based AT in these contexts over extended periods of time. Children need time to increase their eye gaze performance, and establish new habits for performing activities with gaze-based AT. In addition, key persons in the children's immediate environment also need time to acquire knowledge and skills in adapting activities to be able to support the child and ensure sustained gaze-based AT usage over time. Based on the findings of this thesis, decisions about the provision of gaze-based AT should not be made based only on a few early assessments of children's gaze control skills for activities. Instead, allowing children to perform daily activities with gaze-based AT in real life and over several months is needed to assess outcomes from its use. This implies the need for long trial periods in real life for provision of gaze-based AT.

The gaze-based AT's positive impact on the children's daily activities means that other children with similar impairments should be investigated and assessed to determine what benefits they may gain from gaze-based AT use. A crucial part of this assessment is the involvement of key persons in the immediate environment of the child. Without these key personnel, the chances of maintaining successful gaze-based AT usage over time are minimised, which in turn will impact on the children's use of gaze-based AT for activities.

Another important implication is that activities the children control by their gaze should be based on the children's preferences and interests, so that they are motivated to further develop and maintain their gaze control skills. Through exploration of meaningful activities, children will both enhance their gaze control skills and benefit from this AT usage in their daily activities. Thus, even though communication might seem to be the most important activity for teachers and 
parents, the children's motivation to start other activities to discover what benefits they may gain from the AT should not be ignored.

To maintain an activity repertoire with gaze-based AT parents may need guidance and support from professionals in how to provide the child with the right level of intriguing and challenging activities over time, due to the child's progressively changing needs. Even though some parents will learn how to adapt the content, they may still need guidance in assessing what the next step should be in providing new and challenging activities.

\section{METHODOLOGICAL CONSIDERATIONS}

A limitation of the thesis is that only ten children participated in Studies II-IV (their parents in Study IV), and due to this small sample size, the results need to be interpreted carefully. These children represented a small group of children. The prevalence of cerebral palsy is two of 1000 live births (Himmelmann et al., 2005), of which only about $30 \%$ have a severe motor impairment (Himmelmann \& Uvebrant, 2011) and about one in four are non-verbal (Novak et al., 2012; Zhang, Oskoui, \& Shevell, 2015). However, to be eligible for gaze-based AT two more criteria need to be fulfilled, viz.: children must have such severe motor impairments that they only can control a computer with eye gaze. In addition, children need to have sufficient cognitive level to be able to use gaze-based AT in daily activities. Based on this, it may be speculated that about 20-25 children could be eligible for gaze-based AT in the catchment area for the regional paediatric rehabilitation centre. Even though only ten children were included, Studies II and III represented a total survey as all children that were referred to one of the regional paediatric rehabilitation centres over a period of three years were included in this thesis. However, a larger group of children may have revealed more variations in the use and outcomes of the gaze-based AT. Even though the children in Studies II-IV had the same level of severe motor impairments and communicative difficulties, there was variability in concomitant impairments, for example in cognitive level, epilepsy, and vision impairments, 
which reflects the heterogeneity in children with severe physical impairments (Himmelmann \& Uvebrant, 2011). This may indicate that there would be more variation in gaze-based AT outcomes in a larger group of children.

Another limitation in this thesis is the limited information of children's cognitive levels. Research shows that cognitive impairment is more common among children with severe motor impairment and with severe communication difficulties (Himmelmann \& Uvebrant, 2011). However, without the ability to communicate and express themselves it is difficult for children to participate in assessments (Yin Foo et al., 2013). Thus, children need to be provided with opportunities to express themselves, such as gaze-based AT, for others to learn more about their cognitive level.

The longitudinal design of three of the studies permitted us to capture changes in outcomes over time. Hence, if changes come earlier than five months (Studies II, III) this could not be captured with the spacing between time points that was used in this thesis. Decisions on the timing and frequency of measurements are some of the main challenges of longitudinal designs (Ployhart \& Vandenberg, 2010). Nevertheless, the timing of five months as the first time point was decided due to the estimation of time needed for key persons to learn how to handle and support children in use of the AT (Anderson et al., 2013; Desideri et al., 2014; Donegan, 2012; van Niekerk \& Tönsing, 2014). In addition, several months has been suggested as necessary to fully implement other ATs for children with complex needs (Salminen, et al., 2004). Thus, giving the recommendation of a frequency of at least three repeated measurements in longitudinal designs (Ployhart \& Vandenberg, 2010), the frequency of three and four time points spaced over 1520 months can be seen as sufficient for the longitudinal designs of Studies II and III. 
Embedding a qualitative approach in the longitudinal design (Calman, Brunton, \& Molassiotis, 2013) could have contributed to providing knowledge about the intervention in Study II. The measurements used in Study II reveal that intervention works, but equally important are the mechanisms of how the intervention works (Lenker et al., 2010). It cannot be concluded from this thesis if some key elements are more influential than others in maintained use of gazebased AT (e.g. increased knowledge, collaboration between key persons, child's preferences for usage and goal setting). Embedding qualitative interviews with parents, teacher and professionals, and focusing on changes between the time points may have given answers concerning how the different key elements of interventions (Studies I and II) contribute to the change in outcomes, which would have been valuable knowledge. Difficulty in determining the relative contributions from different active ingredients is a common problem in complex interventions (Craig et al., 2008; Lenker et al., 2010). Nevertheless, the combination of key elements (Study I, II) was used because previous research indicates these elements to be of significance in intervention studies with children with physical impairments.

Doing a pilot study of two of the components of the intervention (course day and planning meeting) proved to be a good decision. Due to the indication that more support was needed for teachers after the AT intervention concerning the use of computers in school activities (Study I), it was decided that greater efforts needed to be made to support teachers concerning children's use of gaze-based AT in daily activities. Furthermore, the pilot study revealed that the procedures and instruments for data collection worked.

Both the pilot study (Study I) and the GAT intervention (Study II) were implemented in real school settings (Study I) and a clinical setting (Study II). A strength of the pilot study was that it was implemented in 14 different mainstream schools, which shows that the basic components tested can work in different school settings, and that teachers generally thought goal setting was 
feasible to use in their daily educational work. However, a challenge of implementation in real settings can be that internal validity is compromised, and it is not possible to know if the intervention is solely responsible for the changes observed, or if there are external factors that contribute (Fuhrer, 2003). Medical records showed that there were no other competing interventions concerning AT that were implemented during the time period of the GAT intervention (Studies II-III).

Actively taking part in activities is an important dimension of participation, although the child's subjective experience also needs to be considered to more fully understand children's participation in everyday activities (Almqvist \& Granlund, 2005; Hemmingsson \& Jonsson, 2005). The children's own experiences have not been investigated in this thesis, but based on parents' experiences (Study IV), children made their own choices and showed selfdetermination in gaze-based AT usage, which may be an indication of what activities they perceived as meaningful to participate in.

\section{CONCLUSIONS}

The thesis show that these children with severe physical impairments without speech acquired sufficient gaze control skills to use gaze-based AT to perform daily activities in home and at school. The gaze-based AT had positive impact on children's activity repertoire and on their opportunities to perform activities. When using gaze-based AT children performed for example play activities, communication- and interaction related activities, school activities and they also demonstrated self-determination. For the parents, children's gaze-based AT usage made a difference since it brought out a shift in parents' view on their children and shaped a hope of a better future for their children, where they can use their inherent potential to develop and gain influence in their future life. Furthermore, the children continued to perform daily activities with gaze-based AT over time which suggests that key persons were provided with sufficient 
knowledge and skills to support children in maintained use of gaze-based AT after withdrawal of the services provided in the GAT intervention.

\section{FUTURE RESEARCH}

The findings of the current thesis suggest that the use of gaze-based AT in a small group of children give positive impact on children's daily activities. Further research is needed to replicate the study's findings in larger sample of children with complex needs. A large enough sample would also allow for comparison of outcomes from gaze-based AT usage for different subgroups of children based on covariates such as age, gender, or diagnosis. In addition, with an occupational perspective of doing, future research should also address children's health-related quality of life concerning the use of gaze-based AT.

The findings in this thesis suggest that a service delivery model consisting of collaborative meetings, course days and individual support show positive outcomes for children. In future research it would be valuable to compare outcomes due to service delivery provided. Replication of the model in a larger more heterogeneous sample could be beneficial to inform service delivery for these children. This would give insights about if type of service delivery makes differences on children's long-term use.

The findings that communication and social interaction was an important area of gaze-based AT use, and that several purposes of communication was targeted, highlights the need of assessing communication and interaction skills in research concerning gaze-based AT. For example, observing initiatives and spontaneous communication, turn-taking, and purpose of communication when using gazebased AT during interaction with other people would give valuable knowledge about children's communication skills related to gaze-based AT use. In addition, independence during gaze-based AT usage is another important area to be researched in future. 


\section{SVENSK SAMMANFATTNING}

Det finns en grupp barn som har omfattande rörelsehinder och som saknar tal. Dessa barn har viljemässigt endast full kontroll på ögonrörelser av alla kroppsrörelser. Barnen är beroende av full assistans i alla dagliga aktiviteter såsom för att äta, leka eller kommunicera. Föräldrar ställer vanligtvis ja och nej frågor som barnen besvarar med olika ansiktsuttryck och genom att titta i olika riktningar med ögonen. Att styra en dator med ögonen kan vara barnens enda möjlighet att utföra aktiviteter. Ögonstyrd dator har därför potential att förse barnen med möjligheter att till exempel leka, utföra skoluppgifter och kommunicera, men forskning saknas kring vilken påverkan användning av hjälpmedlet kan ha på barnens dagliga aktiviteter.

Avhandlingens syfte var att undersöka vilken effekt ögonstyrd dator som hjälpmedel har på dagliga aktiviteter för barn med omfattande rörelsehinder som saknar tal. Syftet var också att utveckla och pröva en intervention för ögonstyrd dator i hemmet och skolan för barnen och få förståelse för hjälpmedlets inverkan på dagliga aktiviteter utifrån föräldrars erfarenheter.

En intervention för ögonstyrd dator utvecklades och först prövades interventionens två grundkomponenter.

I första delstudien deltog 15 elever med rörelsehinder samt deras lärare. I denna delstudie prövades två av komponenterna i interventionen; kursdag för lärare samt gemensamt planeringsmöte för elev, lärare och arbetsterapeut. Syftet var att förbättra användningen av tillgängliga datorer i skolarbetet för eleverna. Delstudien visade att eleverna förbättrade utförandet av skolaktiviteter med dator relaterat till de mål som sattes upp under interventionen. Delstudien visade också att interventionen hade avsedd effekt men att mer stöd behövdes till lärarna. Efter första delstudien utvecklades interventionen ytterligare, med inriktning mot ögonstyrd dator och barn med omfattande rörelsehinder utan tal. Tio barn $\mathrm{i}$ åldrarna 1-15 år deltog sedan i interventionen tillsammans med sina föräldrar och lärare. Interventionen bestod av att ha tillgång till ögonstyrd dator i skolan och hemmet samt att få stöd från ett multiprofessionellt kommunikationsteam under nio till tio månader. Interventionen syftade till att stödja användningen av ögonstyrd dator i dagliga aktiviteter. När interventionen avslutats fortsatte barnen att ha full tillgång till ögonstyrd dator. Barnens användning av ögonstyrd dator följdes under 15-20 månader. De följande tre delarbetena rör ögonstyrd dator för dessa tio barn.

I den andra delstudien, som var en longitudinell studie, utvärderades interventionen för ögonstyrd dator med avseende på aktivitetsrepertoar, omfattning av användning $\mathrm{i}$ dagliga aktiviteter, måluppfyllelse samt föräldrars 
nöjdhet med hjälpmedlet och med erhållet stöd under interventionen. Delstudien visade att barnen använde den ögonstyrda datorn för att utföra dagliga aktiviteter både $\mathrm{i}$ hemmet och i skolan. Aktivitetsrepertoaren ökade med användning av ögonstyrd dator och alla barn uppfyllde mål med användningen. Alla barn fortsatte också att utföra aktiviteter med ögonstyrd dator i hemmet och skolan efter avslutat stöd från teamet. Delstudien visade också att föräldrarna var nöjda med hjälpmedlet och med det stöd de fick under interventionen.

I den tredje delstudien, som var en longitudinell studie, utvärderades barnens förmåga att styra datorn med ögonen med avseende på tid och precision i utförandet. Studien visade att barnen förbättrade sin förmåga att styra datorn med ögonen över lång tid och att barnen hade bäst precision i utförandet vid 15 till 20 månader efter att de börjat använda ögonstyrd dator för dagliga aktiviteter.

I den fjärde delstudien intervjuades föräldrar till åtta av barnen med syftet att förstå vad det betyder för föräldrarna att deras barn med omfattande rörelsehinder utan tal får tillgång till och börjar använda ögonstyrd dator i dagliga aktiviteter. Studien visade att för föräldrarna gjorde användningen av ögonstyrd dator skillnad då barnen med hjälp av den ögonstyrda datorn kunde utföra aktiviteter själva vilket de inte kunde göra tidigare. Barnens personlighet och kompetens blev mer synlig för föräldrarna när barnen använde den ögonstyrda datorn. Användningen medförde också att barnen uttryckte självbestämmande såsom att utrycka egna upplevda behov samt sin vilja. För föräldrarna innebar barnens användning av ögonstyrd dator oändliga möjligheter för barnens lärande och ett hopp om en framtid där barnen kan utvecklas och påverka sitt liv.

Sammantaget visar avhandlingen att dessa barn med omfattande rörelsehinder utan tal, erövrade tillräckliga färdigheter i att kontrollera en dator med ögonen för att utföra dagliga aktiviteter via ögonstyrning. Ögonstyrda datorn hade en positiv inverkan på barnens aktivitetsrepertoar och på deras möjligheter att utföra aktiviteter. Barnen utförde bland annat lekaktiviteter, kommunikations- och interaktionsrelaterade aktiviteter, skolaktiviteter och visade även självbestämmande vid användning av ögonstyrd dator. För föräldrarna innebar den inverkan användningen hade på dagliga aktiviteter ett hopp om att barnen ska kunna utvecklas och påverka sitt liv i framtiden. Vidare visar avhandlingen att barnen fortsatte använda ögonstyrd dator i dagliga aktiviteter efter avslutad intervention. Den kan betyda att interventionen försåg föräldrar och lärare med tillräckliga kunskaper för att stödja barnen $i$ fortsatt användning av hjälpmedlet även efter att stödet $i$ interventionen avslutats. 


\section{ACKNOWLEDGEMENTS}

I want to express my warmest and deepest thanks to all that have contributed in different ways to my thesis. In particular I wish to thank;

All children, parents and teachers who wanted to be part of this project. Thank you for sharing your experiences; without you this thesis could not have been written.

Thank you also to Tobii Technology for lending us some of the equipment which made this research possible.

Helena Hemmingsson, my main supervisor, for believing in this project and for sharing your knowledge with me. You inspire me. You never stop challenging my thoughts, and that makes me grow. I have learned so much from you.

Torbjörn Falkmer, my co-supervisor, for being available and highly present from down under, always supporting and willing to give comments and guidance. Thank you for your great generosity.

Jan Sandqvist and Gunnar Ahlsten, my co-supervisors, for guidance during this journey. Janne, you made me sharpen my arguments on methods, and Gunnar, thank you for believing in me and for sharing your knowledge of children with impairments.

Senior researchers and doctoral students at the divisions of Occupational Therapy and Nursing Science for valuable discussions during seminars.

My deepest thanks to Christina, Anna, Anna, Anita and Anne at Folke Bernadotte regional habilitation centre $(\mathrm{FBH})$, for your engagement, and for sharing your important clinical experiences of children with profound impairments with me. You are always deeply engaged with the children and your work makes me proud. A special thank you also to the staff at FBH for supporting me with valuable time.

Special thanks to my beloved ones, Pär-Ola, Jesper and Ida; you are always in my heart, you are the best. Thank you PO for your support, for your patience, and for forcing me to take some breaks during the last part of the Phd marathon. 
This research was supported by Vetenskapsrådet, Jimmy Dahlstens fond, Stiftelsen Sunnerdahls handikappfond, Linköping University, and Uppsala CountyCouncil.

Maria Borgestig 


\section{REFERENCES}

Almqvist, L., A., Granlund, M. (2005). Participation in school environment of children and youth with disabilities: A person-oriented approach. Scandinavian Journal of Psychology, 46, 305-314.

Anderson, K., Balandin, S., \& Stancliffe, R. (2014). Australian parents' experiences of speech generating device (SGD) service delivery. Developmental Neurorehabilitation, 17(2), 75-83.

Antle, B., Mills, W., Steele, C., Kalnins, I., \& Rossen, B. (2008). An exploratory study of parents' approaches to health promotion in families of adolescents with physical disabilities. Child: Care, Health and Development, 34(2), 185-193.

Arthanat, S., Bauer, S. M., Lenker, J. A., Nochajski, S. M., \& Wu, Y. W. B. (2007). Conceptualization and measurement of assistive technology usability. Disability \& Rehabilitation: Assistive Technology, 2(4), 235-248.

Arthanat, S., Nochajski, S. M., Lenker, J. A., Bauer, S. M., \& Wu, Y. W.B. (2009). Measuring usability of assistive technology from a multicontextual perspective: The case of power wheelchairs. The American Journal of Occupational Therapy, 63(6), 751-764.

Arvidsson, P., Granlund, M., \& Thyberg, M. (2015). How are the activity and participation aspects of the ICF used? Examples from studies of people with intellectual disability. NeuroRehabilitation, 36, 45-49.

Ball, L., Nordness, A., Fager, S., Kersch, K., Mohr, B., Pattee, G., \& Beukelman, D. (2010). Eye-gaze access of AAC technology for persons with amyotrophic lateral sclerosis. Journal Medical Speech Language Pathology, 18, 11-23.

Batorowicz, B., Campbell, F., von Tetzchner, S., King, G., \& Missiuna, C. (2014). Social participation of school-aged children who use communication aids: The views of children and parents. Augmentative and Alternative Communication, 30(3), 237-251.

Baxter, S., Enderby, P., Evans, P., \& Judge, S. (2012). Barriers and facilitators to the use of high-technology augmentative and alternative communication devices: A systematic review and qualitative synthesis. International Journal of Language \& Communication Disorders, 47(2), 115-29.

Beckung, E., \& Hagberg, G. (2002). Neuroimpairments, activity limitations, and participation restrictions in children with cerebral palsy. Developmental Medicine \& Child Neurology, 44(5), 309-316.

Beckung, E., White-Koning, M., Marcelli, M., McManus, V., Michelsen, S., Parkes, J.,... Fauconnier, J. (2008). Health status of children with cerebral palsy living in Europe: A multi-centre study. Child: Care, Health and Development, 34(6), 806814.

Beukelman, D. R. \& Mirenda, P. (2013). Augmentative \& alternative communication. Supporting children \& adults with complex communication needs. (4 ed.).

Baltimore: Paul H. Brookes Publishing Co.

Brodin, J., \& Renblad, K. (2009). How many positive results on inclusion do we need to make a change? In P. L. Emiliano et al. (Eds.), Assistive technology from adapted equipment to inclusive environments AAATE. Amsterdam: IOS Press. 
Bottcher, L. (2010). Children with spastic cerebral palsy, their cognitive functioning, and social participation: A review. Child Neuropsychology, 16(3), 209-228. doi:10.1080/09297040903559630

Brodin, J., \& Lindstrand, P. (2003). What about ICT in special education? Special educators evaluate information and communication technology as a learning tool. European Journal of Special Needs Education, 18, 71-87.

Caligari, M., Godi, M., Guglielmetti, S., Franchignoni, F., \& Nardone, A. (2013). Eye tracking communication devices in amyotrophic lateral sclerosis: Impact on disability and quality of life. Amyotrophic Lateral Sclerosis and Frontotemporal Degeneration, 14, 546-552.

Calman, L., Brunton, L., \& Molassiotis, A. (2013). Developing longitudinal qualitative designs: Lessons learned and recommendations for health services research. $B M C$ Medical Research Methodology, 13(14), 1-10. doi:10.1186/1471-2288-13-14

Case-Smith, J., \& O'Brien, J. C. (2010). Occupational therapy for children (6th ed.). Maryland Heights, Mo.: Mosby/Elsevier.

Caltenco, H. A., Breidegard, B., \& Andreasen Struijk, L. N. S. (2014). On the tip of the tongue: learning typing and pointing with an intra-oral computer interface. Disability and Rehabilitation: Assistive Technology, 9(4), 307-317.

Carpe, A., Harder, K., Tam, C., \& Reid, D. (2010). Perceptions of writing and communication aid use among children with a physical disability. Assistive Technology, 22, 87-98.

Chantry, J., \& Dunford, C. (2010) How do computer assistive technologies enhance participation in childhood occupations for children with multiple and complex disabilities? A review of the current literature. British Journal of Occupal Therapy, 73(8), 351-365.

Chin, C. A., Barreto, A., Cremades, J. G., \& Adjouadi, M. (2008). Integrated electromyogram and eye-gaze tracking cursor control system for computer users with motor disabilities. Journal of Rehabilitation Research \& Development, 45(1), 161-174.

Compagnone, E., Maniglio , J., Camposeo , S., Vespino , T., Losito , L., De Rinaldis, M.,... Trabacca, A. (2014). Functional classifications for cerebral palsy: Correlations between the gross motor function classification system (GMFCS), the manual ability classification system (MACS) and the communication function classification system (CFCS). Research in Developmental Disabilities, 35, 26512657.

Cook, A. M. (2009). Ethical Issues Related to the Use/Non-Use of Assistive Technologies. Developmental Disabilities Bulletin, 37, (1 \& 2), 127-152.

Cook, A. M., \& Polgar, J. M. (2015). Assistive technologies: Principles and practice. St. Louis, Missouri: Elsevier Health Sciences.

Copley, J., \& Ziviani, J. (2004). Barriers to the use of assistive technology for children with multiple disabilities. Occupational Therapy International, 11(4), 229-43.

Craddock, G. (2006). The AT continuum in education: Novice to power user. Disability and Rehabilitation: Assistive Technology, 1, 17-27.

Craig P, Dieppe P, Macintyre S, Michie S, Nazareth I, Petticrew M. (2008). Developing and evaluating complex interventions: The new Medical Research Council guidance. British Medical Journal, 337, 979-83

Davis, J., \& Polatajko, H. (2006). The occupational development of children. In S. Rodger, \& J. Ziviani, (Eds.), Occupational therapy with children: Understanding children's occupations and enabling participation. Oxford: Blackwell. 
Demers, L., Weiss-Lambrou, R., \& Ska, B. (2002). The Quebec user evaluation of satisfaction with assistive technology (QUEST 2.0): An overview and recent progress. Technology and Disability, 14(3), 101-105.

Demers, L., Weiss-Lambrou, R. \& Ska, B. (1996). Quebec User Evaluation of Satisfaction with Assistive Technology QUEST version 2.0. An outcome measure for assistive technology devices. Retrieved November 03, 2015, from http://dx.doi.org/10.13072/midss.298

Desideri, L., Stefanelli, B., Bitelli, C., Roentgen, U., Gelderblom, G., \& de Witte, L. (2014) Satisfaction of users with assistive technology service delivery: An exploratory analysis of experiences of parents of children with physical and multiple disabilities. Developmental Neurorehabilitation, 30, 1-12.

Dettmer, P., Dyck, N., \& Thurston, L. P. (2005). Consultation, collaboration, and teamwork for students with special needs. (5th ed). Boston, MA: Allyn \& Bacon.

Dhas, B. N., Samuel, P. S., \& Manigandan, C. (2014). Use of computer access technology as an alternative to writing for a pre-school child with athetoid cerebral palsy - A case report. Occupational Therapy in Health Care, 28(3), 318-332.

Diard, J., Rynik, V., \& Lorenceau, J. (2013). A bayesian computational model for online character recognition and disability assessment during cursive eye writing. Frontiers in psychology, 4, 1-14.

Donegan, M. (2012). Participatory design: The story of Jayne and other complex cases. In P. Majaranta, H. Aoki, M. Donegan, D.W. Hansen, J.P. Hansen, A. Hyrskykari \& K. Räihä (Eds.), Gaze interaction and applications of eye tracking: Advances in assistive technologies (pp. 55-61). Hershey: Medical Information Science Reference.

Donegan, M., Morris, J. D., Corno, F., Signorile, I., Chió, A., Pasian, V., ... Holmqvist, E. (2009). Understanding users and their needs. Universal Access in the Information Society, 8(4), 259-275.

Donegan, M., \& Oosthuizen, L. (2006). The "KEE" concept for eye-control and complex disabilities: Knowledge-based, end user-focused and evolutionary. Proceedings of the $2^{\text {nd }}$ conference on Communication by Gaze Interaction (COGAIN). Retrieved May 30, 2015, from http://wiki.cogain.org/index.php/Downloads

Drager, K., Light, J., \& McNaughton, D. (2010). Effects of AAC interventions on communication and language for young children with complex communication needs. Journal of Pediatric Rehabilitation Medicine, 3(4), 303-310. doi:10.3233/PRM-2010-0141

Eftring, H. (1999). The useworthiness of robots for people with physical disabilities. (Doctoral dissertation, Lund University, Department of Design Sciences, Sweden). Retrieved from http://www.certec.lth.se/

Eliasson, A. C., Krumlinde-Sundholm, L., Rosblad, B., Beckung, E., Arner, M., Ohrvall, A. M., \& Rosenbaum, P. (2006). The manual ability classification system (MACS) for children with cerebral palsy: Scale development and evidence of validity and reliability. Developmental Medicine and Child Neurology, 48(7), 549554.

Fuhrer, M. J. (2003). Overview of Clinical Trials in Medical Rehabilitation Impetuses, Challenges, and Needed Future Directions. American Journal of Physical Medicine \& Rehabilitation, 82(10), s8-15.

Fuhrer, M. J., Jutai, J. W., Scherer, M. J., \& DeRuyter, F. (2003). A framework for the conceptual modelling of assistive technology device outcomes. Disability and Rehabilitation, 25(22), 1243-1251. 
Gadamer, H. G. (2004). Truth and method. New York: Continuum Publishing Group.

Godijn, R., \& Theeuwes, J. (2004). The relationship between inhibition of return and saccade trajectory deviations. Journal of Experimental Psychology: Human Perception and Performance, 30(3), 538 - 554.

Graham, A., Powell, M., Taylor, N., Anderson, D. \& Fitzgerald, R. (2013). Ethical Research Involving Children. Florence: UNICEF Office of Research - Innocenti.

Granlund, M., Björck-Åkesson, E.,Wilder, J., \& Ylven, R. (2008). AAC interventions for children in a family environment: Implementing evidence in practice. Augmentative Alternative Communication, 24(3), 207-19.

Hansen, D. W., \& Majaranta, P. (2012). Basics of camera-based gaze tracking. In P. Majaranta, H. Aoki, M. Donegan, D. W. Hansen, J. P. Hansen, A. Hyrskykari \& K. Räihä (Eds.), Gaze interaction and applications of eye tracking: Advances in assistive technologies (pp. 21-26). Hershey: Medical Information Science Reference.

Hansen, J. P., \& Aoki, H. (2011). Methods and measures: An introduction. In P. Majaranta, H. Aoki, M. Donegan, D. W. Hansen, J. P. Hansen, A. Hyrskykari \& K. Räihä (Eds.), Gaze interaction and applications of eye tracking: Advances in assistive technologies (pp. 197-204). Hershey: Medical Information Science Reference.

Hasselbring, T. S., \& Glaser, C. H. W. (2000) Use of computer technology to help students with special needs. The Future of Children, 10(2), 102-122.

Heikkilää, H., \& Ovaska, S. (2012). Usability evaluation of gaze interaction. In P. Majaranta, H. Aoki, M. Donegan, D. W. Hansen, J. P. Hansen, A. Hyrskykari \& K. Räihä (Eds.), Gaze interaction and applications of eye tracking: Advances in assistive technologies (pp. 255-278). Hershey: Medical Information Science Reference.

Hemmingsson, H. (2002). Student-environment fit for students with physical disabilities. Stockholm: Karolinska University Press.

Hemmingsson, H., Gustavsson, A., \& Townsend, E. (2007). Students with disabilities participating in mainstream schools: Policies that promote and limit teacher and therapist cooperation. Disability \& Society, 22(4), 383-398.

Hemmingsson, H., \& Jonsson, H. (2005). An occupational perspective on the concept of participation in the international classification of functioning, disability and health-some critical remarks. The American Journal of Occupational Therapy: Official Publication of the American Occupational Therapy Association, 59(5), 569-576.

Hemmingsson, H., Lidstrom, H., Nygard, L. (2009) Use of assistive technology devices in mainstream schools: Students' perspective. The American Journal of Occupational Therapy, 63(4), 463-472.

Hewitt-Taylor, J. (2008). Parents' views of their children who have complex health needs. Paediatric Nursing, 20(8), 20-23.

Hidecker, M. J. C., Paneth, N., Rosenbaum, P. L., Kent, R. D., Lillie, J., Eulenberg, J. B., ... Evatt, M. (2011). Developing and validating the communication function classification system for individuals with cerebral palsy. Developmental Medicine \& Child Neurology, 53(8), 704-710.

Himmelmann, K., Hagberg, G., Beckung, E., Hagberg, B., \& Uvebrant, P. (2005). The changing panorama of cerebral palsy in Sweden. IX. Prevalence and origin in the birth-year period 1995-1998. Acta Paediatrica, 94(3), 287-294.

Himmelmann, K., Lindh, K., \& Hidecker, M. J. C. (2013). Communication ability in cerebral palsy: A study from the CP register of western Sweden. European Journal of Paediatric Neurology, 17(6), 568-574. 
Himmelmann, K., \& Uvebrant, P. (2011) Function and neuroimaging in cerebral palsy: A population-based study. Developmental Medicine \& Child Neurology, 53(6), 516-521.

Hoppestad, B. S. (2007) Inadequacies in computer access using assistive technology devices in profoundly disabled individuals: An overview of the current literature. Disability \& Rehabilitation: Assistive Technology, 2(4), 189-199.

Hornof, A. J., \& Cavender, A. (2005). EyeDraw: Enabling children with severe motor impairments to draw with their eyes. Proceedings of the SIGCHI Conference on Human Factors in Computing Systems, New York: ACM, 161-170.

Hwang, C. S., Weng, H. H., Wang, L. F., Tsai, C. H., \& Chang, H. T. (2014). An eyetracking assistive device improves the quality of life for ALS patients and reduces the caregivers' burden. Journal of Motor Behavior, 46(4), 233-238. doi:10.1080/00222895.2014.891970

ISO (1998). ISO 9241-11. Ergonomic requirements for office work with visual display terminals (VDTs): Part 11: Guidance on usability. Retrieved November 03, 2015, from http://www.iso.org/iso/home.html

ISO. (2011). ISO 9999:2011. Assistive products for persons with disability classification and terminology. Retrieved December 19, 2014, from http://www.iso.org/iso/

Jenko, M., Matjacic, Z., Vidmar, G., Bester, J., Pogacnik, M., \& Zupan, A. (2010). A method for selection of appropriate assistive technology for computer access. International Journal of Rehabilitation Research, 33, 298-305.

Jutai, J., \& Day, H. (2002). Psychosocial impact of assistive devices scale (PIADS). Technology and Disability, 14(3), 107-111.

Kaplan, M. (2010). A frame of reference for motor skill acquisition. In P. Kramer, \& J. Hinojosa. Frames of reference for pediatric occupational therapy (3rd ed.). Philadelphia: Wolters Kluwer Health/Lippincott Williams \& Wilkins.

Kielhofner, G. (2008). Model of human occupation: Theory and application (4th ed.). Baltimore, MD: Lippincott Williams \& Wilkins.

Kiresuk, T. J., Smith, A., \& Cardillo, J. E. (1994) Goal attainment scaling: Applications, theory, and measurement. Hillsdale, NJ: Lawrence Erlbaum.

Kirkwood, B. R., \& Sterne, J. A. C. (2003). Essential medical statistics (2nd ed.). Malden, Mass.: Blackwell Science.

Koester, H., LoPresti, E., \& Simpson, R. (2011). Further validation of the "aim" test for assessing a user's mouse skills. Proceedings of the RESNA Annual Conference. Toronto Arlington: RESNA Press.

Koester, H. H., Simpson, R. C., Spaeth, D. \& LoPresti, E. (2007). Reliability and validity of compass software for access assessment. Proceedings of the RESNA Annual Conference. Phoenix AZ Arlington: RESNA Press.

Kramer, P., \& Hinojosa, J. (2009). Frames of reference for pediatric occupational therapy (3rd ed.) Philadelphia : Wolters Kluwer Health/Lippincott Williams \& Wilkins.

Lariviere, J. A. (2014). Eye tracking: Eye gaze technology. In I. Söderback (Ed.). International Handbook of Occupational Therapy Interventions (pp. 339-362). New York: Springer.

Law, M. (2002). Participation in the occupations of everyday life. The American Journal of Occupational Therapy, 56(6), 640 - 649.

Lenker, J. A., Fuhrer, M. J., Jutai, J. W., Demers, L., Scherer, M. J., \& DeRuyter, F. (2010). Treatment theory, intervention specification, and treatment fidelity in assistive technology outcomes research. Assistive Technology, 22(3), 129-138. 
Lenker, J. A., \& Paquet, V. L. (2003). A review of conceptual models for assistive technology outcomes research and practise. Assistive Technology, 15:1-15.

Lenker, J. A., \& Paquet, V. L. (2004). A new conceptual model for assistive technology outcomes research and practice. Assistive Technology, 16(1), 1-10.

Lenker, J. A., Scherer, M. J., Fuhrer, M. J., Jutai, J. W., \& DeRuyter, F. (2005). Psychometric and administrative properties of measures used in assistive technology device outcomes research. Assistive Technology: The Official Journal of RESNA, 17(1), 7-22.

Lidström H, Almqvist L, Hemmingsson H. (2012). Computer-based assistive technology device for use by children with physical disabilities: A cross-sectional study. Disability and Rehabilitation: Assistive Technology, 7, 287-293.

Lidström, H., \& Borgestig, B. (2008). Assistive technology devices in computer activities. In A-C. Eliasson \& P.A. Burtner (Eds.). Improving hand function in children with cerebral palsy: theory, evidence and intervention. London: Mac Keith Press.

Lidström, H., Granlund, M., \& Hemmingsson, H. (2012). Use of ICT in school: A comparison between students with and without physical disabilities. European Journal of Special Needs Education, 27(1), 21-34.

Light, J., \& Drager, K. (2007). AAC technologies for young children with complex communication needs: State of the science and future research directions. Augmentative and Alternative Communication, 23 (3), 204-216

Light, J., \& McNaughton, D. (2012). Supporting the communication, language, and literacy development of children with complex communication needs: State of the science and future research priorities. Assistive Technology, 24(1), 34-44.

Lin, C., Yang, H., Lay, Y., \& Yang, S. (2011). Design and evaluation of a public installation of an eye-gaze system. Assistive Technology, 23(4), 187-198.

Lindsay, L. (2010). Perceptions of health care workers prescribing augmentative and alternative communication devices to children. Disability and Rehabilitation: Assistive Technology, 5(3): 209-222.

Majaranta P, Aoki H, Donegan M, Hansen DW, Hansen JP, Hyrskykari A, Räihä K (2012). Gaze interaction and applications of eye tracking: Advances in assistive technologies. Hershey: Medical Information Science Reference

Majaranta, P., \& Donegan, M. (2012). Introduction to gaze interaction. In P. Majaranta, H. Aoki, M. Donegan, D. W. Hansen, J. P. Hansen, A. Hyrskykari \& K. Räihä (Eds.), Gaze interaction and applications of eye tracking: Advances in assistive technologies (pp. 1-9). Hershey: Medical Information Science Reference.

Majnemer, A., Shevell, M., Law, M., Birnbaum, R., Chilingaryan, G., Rosenbaum, P., Poulin, C. (2008) Participation and enjoyment of leisure activities in school-aged children with cerebral palsy. Developmental Medicine \& Child Neurology, 50(10), 751-758.

Man, D. W. K, \& Wong, M. L. (2007). Evaluation of computer-access solutions for students with quadriplegic athetoid cerebral palsy. American Journal of Occupational Therapy, 61, 355-364.

Martin, J. K., Martin, L. G., Stumbo, N. J., \& Morrill, J. H. (2011) The impact of consumer involvement on satisfaction with and use of assistive technology. Disability and Rehabilitation: Assistive Technology, 6(3), 225-242.

Mattingly, C. (2010). The paradox of hope: Journeys through a clinical borderland. Los Angeles: Univ of California Pr.

McNaughton, D., Benedek-Wood, E., Light, J., Rackensperger, T., Krezman, C., \& Williams, M. (2008). "A child needs to be given a chance to succeed": Parents of 
individuals who use AAC describe the benefits and challenges of learning AAC technologies. AAC: Augmentative and Alternative Communication, 24(1), 43-55. doi:10.1080/07434610701421007

Mei, C., Reilly, S., Reddihough, D., Mensah, F., Green, J., Morgan, A.T., \& Pennington, L. (2015). Activities and participation of children with cerebral palsy: Parent perspectives. Disability and Rehabilitation, 37(23), 2164-2173. doi:10.3109/09638288.2014.999164

Molin, M. (2004). Delaktighet inom handikappområdet-en begreppsanalys. In A. Gustavsson (Ed.), Delaktighetens Språk. Lund: Studentlitteratur.

Mulvey, F. (2012). Eye anatomy, eye movements and vision. In P. Majaranta, H. Aoki, M. Donegan, D. W. Hansen, J. P. Hansen, A. Hyrskykari \& K. Räihä (Eds.), Gaze interaction and applications of eye tracking: Advances in assistive technologies (pp. 10-20). Hershey: Medical Information Science Reference.

Mulvey, F., \& Heubner, M. (2011). Eye movements and attention. In P. Majaranta, H. Aoki, M. Donegan, D. W. Hansen, J. P. Hansen, A. Hyrskykari \& K. Räihä (Eds.), Gaze interaction and applications of eye tracking. Advances in assistive technologies (pp. 129-152). Hershey: Medical Information Science Reference.

Myrden, A., Schudlo, L., Weyand, S., Zeyl, T., \& Chau, T. (2014). Trends in communicative access solutions for children with cerebral palsy. Journal of Child Neurology, 29(8) 1108-1118.

Najafi, L., Friday, M., \& Robertson, Z. (2008). Two case studies describing assessment and provision of eye gaze technology for people with severe physical disabilities. Journal of Assistive Technologies, 2(2), 6-12.

Nationalencyklopedin (NE) (2015). Retrieved from http://www.ne.se/

Nielsen, J. (1993). Usability engineering. San Francisco: Morgan Kauffman Publishers.

Novak, I., Hines, M., Goldsmith, S., \& Barclay, R. (2012). Clinical prognostic messages from a systematic review on cerebral palsy. Pediatrics, 130(5), e1285-1312.

Palisano R. J. (1993) Validity of goal attainment scaling in infants with motor delays. Physical Therapy, 73(10), 651-658.

Ottenbacher, K. J. (1986). Evaluating clinical change. Strategies for occupational and physical therapists. Baltimore: Williams \& Wilkins.

Palisano, R., Rosenbaum, P., Walter, S., Russell, D., Wood, E., \& Galuppi, B. (1997). Development and reliability of a system to classify gross motor function in children with cerebral palsy. Developmental Medicine \& Child Neurology, 39(4), 214-223.

Parker, D. C., Burns, M. K., McMaster, K. L., \& Shapiro, E. S. (2012). Extending curriculum-based assessment to early writing. Learning Disabilities Research and Practice, 27(1), 33-43. doi:10.1111/j.1540-5826.2011.00348.x

Patton, M. Q. (2002). Qualitative research \& evaluation methods (3rd ed.). London: SAGE.

Pasqualotto, E., Matuz, T., Ruf, C. A., Bartl, M., Birbaumer, N., Federici, S., ... Halder, S. (2015). Usability and workload of access technology for people with severe motor impairment: A comparison of brain-computer interfacing and eye tracking. Neurorehabilitation and Neural Repair, 29(10), 950-957. doi:10.1177/1545968315575611

Pereira, E., La Cour, K., Jonsson, H., \& Hemmingsson, H. (2010). The participation experience of children with disabilities in Portuguese mainstream schools. The British Journal of Occupational Therapy, 73(12), 598-606.

Peterson, D. B., \& Murray, G. C. (2006). Ethics and assistive technology service provision. Disability and Rehabilitation: Assistive Technology, 1(1-2), 59-67. doi:10.1080/09638280500167241 
Pettersson, I., Ahlström, G., \& Törnquist, K. (2007). The value of an outdoor powered wheelchair with regard to the quality of life of persons with stroke: A follow-up study. Assistive Technology, 19, 143-153.

Pfeiffer, T. (2013). Gaze-based assistive technologies. In G. Kouroupetrglou (Ed.). Assistive Technologies and Computer Access for Motor Disabilities. (pp 90-109). Hershey PA: Medical Information Science Reference.

Ployhart, R. E., \& Vandenberg, R. J. (2010). Longitudinal research: The theory, design, and analysis of change. Journal of Management, 36(1), 94-120. doi:10.1177/0149206309352110

Polit, D. F., \& Beck, C. T. (2008) Nursing research: Generating and assessing evidence for nursing practice (9th ed.). Philadelphia: Lippincott Williams \& Wilkins.

Priest, N., \& May, E. (2001). Laptop computers and children with disabilities: Factors influencing success. Australian Occupational Therapy Journal, 48(1), 11-23.

Raghavendra, P., Olsson, C., Sampson, J., Mcinerney, R., \& Connell, T. (2012). School participation and social networks of children with complex communication needs, physical disabilities, and typically developing peers. Augmentative and Alternative Communication, 28(1), 33-43.

Raghavendra, P., Virgo, R., Olsson, C., Connell, T., Lane, A. E. (2011) Activity participation of children with complex communication needs, physical disabilities and typically-developing peers. Developmental Neurorehabilitation, 14(3), 145-55.

Rose, D. H., Hasselbring, T. S., Stahl, S., \& Zabala, J. (2005). Assistive technology and universal design for learning: Two sides of the same coin. In; D. Edyburn et al. (Eds.), Handbook of special education technology research and practice (pp. 507518). Whitefish Bay, WI: Knowledge by Design.

Rosenbaum, P., Paneth, N., Leviton, A., Goldstein, M., Bax, M., Damiano, D., ... Jacobsson, B. (2007). A report: The definition and classification of cerebral palsy April 2006. Developmental medicine and child neurology Supplement, 109, 8-14.

Ryan, R. M., \& Deci, E. L. (2000). Self-determination theory and the facilitation of intrinsic motivation, social development, and well-being. American Psychologist, 55(1), 68-78. doi:10.1037//0003-066X.55.1.68

Sakzewski, L., Boyd, R., \& Ziviani, J. (2007) Clinimetric properties of participation measures for 5-to 13-year-old children with cerebral palsy: A systematic review. Developmental Medicine \& Child Neurology, 49(3), 232-240.

Salminen, A., Petrie, H., \& Ryan, S. (2004). Impact of computer augmented communication on the daily lives of speech-impaired children. Part I: Daily communication and activities. Technology and Disability, 16, 157-167.

Scherer, M. J. (2002). Assistive technology: Matching device and consumer for successful rehabilitation. London: American Psychological Association.

Skovsgaard, H., Räihä, K., \& Tall, M. (2012). Computer control by gaze. In P. Majaranta, H. Aoki, M. Donegan, D. W. Hansen, J. P. Hansen, A. Hyrskykari \& K. Räihä (Eds.), Gaze interaction and applications of eye tracking: Advances in assistive technologies (pp. 78-102). Hershey: Medical Information Science Reference.

Socialdepartementet (2011). Hur svensk lagstiftning och praxis överensstämmer med rättigheterna i barnkonventionen - en kartläggning. [Swedish legislation and practise in Convention of the Rights of the Child - a survey]. Retreived from: http://www.regeringen.se/contentassets/1150c6261f434d70bb938a52ad5bd710/hursvensk-lagstiftning-och-praxis-overensstammer-med-rattigheterna-ibarnkonventionen---en-kartlaggning-ds-201137 
Spataro, R., Ciriacono, M., Manno, C., \& La Bella, V. (2013). The eye-tracking computer device for communication in amyotrophic lateral sclerosis. Acta Neurologica Scandinavica, 130, 40-45.

Stampe, D. M., \& Reingold, E. M. (1995). Selection by looking: A novel computer interface and its application to psychological research. In J. M. Findlay, R. Walker, R. W. Kentridge (Eds.). Eye Movement Research: Mechanisms, processes and applications (pp. 467-478). Amsterdam: Elsevier Science Publications.

Steenbeek, D., Gorter, J. W., Ketelaar, M., Galama, K., \& Lindeman, E. (2011) Responsiveness of goal attainment scaling in comparison to two standardized measures in outcome evaluation of children with cerebral palsy. Clinical Rehabilitation, 25(12), 1128-1139.

Thirumanickam, A., Raghavendra, P., \& Olsson, C. (2011). Participation and social networks of school-age children with complex communication needs: A descriptive study. Augmentative and Alternative Communication, 27(3), 195-204. doi:10.3109/07434618.2011.610818

Tobii Technology. (2013). Assistive technology products (AAC). Retrieved December 22, 2014, from http://www.tobii.com/en/assistive-technology/global/products/oldor-discontinued-products/

United Nations (1989). Convention on the rights of the child. Retrieved October 04, 2015, from http://www.unicef.org/crc/

van Niekerk, K., \& Tönsing, K. (2015). Eye gaze technology: A South African perspective. Disability and Rehabilitation: Assistive Technology, 10(4):340-6. doi: 10.3109/17483107.2014.974222

Villeneuve, M. (2009). A critical examination of school-based occupational therapy collaborative consultation. Canadian Journal of Occupational Therapy, 76, 20618.

Vygotsky, L. (2012). Thought and language. (Rev. and expanded ed.). London: The MIT Press

Weiss-Lambrou, R. (2002). Satisfaction and comfort. In M. J. Scherer (Ed.). Assistive Technology: Matching Device and Consumer for Successful Rehabilitation. (pp. 77-94). Washington: American Psychological Association. doi:10.1037/10420-005

Wilcock, A. A., \& Hocking, C. (2015). An occupational perspective of health (3rd ed.). Thorofare, N.J.: Slack Incorporated.

WHO (2007). International classification of functioning, disability and health - children and youth version. Retrieved from http://www.who.int/classifications/en/

Yin Foo, R., Guppy, M., \& Johnston, L. M. (2013). Intelligence assessments for children with cerebral palsy: A systematic review. Developmental Medicine \& Child Neurology, 55(10), 911-918.

Zhang, J., Y., Oskoui, M., \& Shevell, M. ( 2015). A Population-Based Study of Communication Impairment in Cerebral Palsy. Journal of Child Neurology, 30(3) 277-284.

Østensjø, S., Carlberg, E. B., \& Vøllestad, N. K. (2005). The use and impact of assistive devices and other environmental modifications on everyday activities and care in young children with cerebral palsy. Disability and Rehabilitation, 2005, 27(14): $849-86$. 



\section{Papers}

The articles associated with this thesis have been removed for copyright reasons. For more details about these see:

http://urn.kb.se/resolve?urn=urn:nbn:se:liu:diva-123303 